\title{
Intrinsic Stability Study of Armodafinil Hydrochloride by Forced Degradation and Impurity Profiling
}

Deepti Jain ${ }^{1}$ and Pawan K Basniwal ${ }^{1,2 *}$

${ }^{1}$ School of Pharmaceutical Sciences, Rajiv Gandhi Technological University, Bhopal - 462033, Madhya Pradesh, India

${ }^{2}$ LBS College of Pharmacy, Jaipur - 302004, Rajasthan, India

\begin{abstract}
Objective: A novel RP-HPLC-DAD-HRMS method was developed for determination of armodafinil in presence of related substances viz. impurities and forced degradation products and its intrinsic stability was established by
\end{abstract} forced degradation profiling.

Method: Armodafinil and its degradation products were successfully separated on Zorbax Eclipse Plus $\mathrm{C} 18$ column $(250 \times 4.6 \mathrm{~mm}, 5 \mu \mathrm{m})$ by mixture of $0.1 \%$ formic acid and acetonitrile (in gradient mode) at $1 \mathrm{ml} / \mathrm{min}$ flow rate within $20 \mathrm{~min}$ and detection was performed by photodiode-array detector at $252 \mathrm{~nm}$.

Results: Drug was extensively degraded in alkaline conditions followed by acidic and neutral conditions, while there was no degradation observed in thermal, oxidative and ultra-violet degradation conditions. Only one impurity (AMD-Imp) was identified as phenylmethanesulfinic acid. Structure of degradation products and degradation pathways of drug have been postulated for hydrolytic condition.

Conclusion: Armodafinil was extensively degraded in basic condition followed by acidic and neutral condition Four DPs vis. AMD3, AMD4, AMD5 and AMD6 were observed in all the conditions. No degradation was found in thermal, UV light and oxidative conditions

Keywords: Intrinsic stability; Armodafinil; Forced degradation profiling; Impurity profiling

\section{Introduction}

Chemically, armodafinil (AMD) is 2-(benzhydryl sulfinyl) acetamide and indicated for use in patients with excessive sleepiness associated with narcolepsy, obstructive sleep apnoea / hypopnoea syndrome or shift work sleep disorder [1]. It is active metabolite of adrafinil [2-(benzhydrylsulfinyl)-N-hydroxyacetamide], which is one of the psycho stimulants having behavioral activating effects.

Although, AMD and its metabolites were analysed by different analytical techniques viz. pharmacokinetics of adrafinil by liquid chromatography / tandem mass spectrometric (LC-MS / MS) method [2]; determination of AMD in human plasma [3] and in plasma and urine [4]; HPLC determination of AMD along with its synthetic intermediates [5,6]; capillary electrophoresis enantiomeric determination [7].

Forced degradation studies provide data to support identification of possible degradants; degradation pathways and intrinsic stability of the drug molecule and validation of stability indicating analytical procedures [8]. Hitherto, as per knowledge of authors, there is no forced degradation studies have been reported in literature including degradation pathway and intrinsic pathway of AMD. The present work was aimed to establish degradation pathway in different degradation conditions by studying the intrinsic stability, forced degradation and impurity profiling of the AMD.

\section{Experimental}

\section{Instrumentation and chromatograph}

HPLC chromatograph was Agilent Infinity 1260 series equipped with 1260 binary pump VL 400 bar, 1260 manual injector 600 bar, Rheodyne 7725i 7-port sample injection valve with $20 \mu \mathrm{L}$ fixed loop, ZORBAX Eclipse Plus C18 $(250 \times 4.6 \mathrm{~mm}, 5 \mu \mathrm{m}), 1260 \mathrm{DAD}$ VL,
$20 \mathrm{~Hz}$ detector, standard flow cell $10 \mathrm{~mm}, 13 \mathrm{~L}, 120 \mathrm{bar}$, OpenLab CDS EZChrom Ed. Workstation and syringe $50.0 \mu \mathrm{L}$, FN, LC tip. All weighing for analysis was performed on Shimadzu electronic analytical balance AX-200. Water used for analysis was prepared by triple distillation assembly. Micromass Q-TOF micro (Waters) liquid chromatography-mass spectrometry (LC-MS) was performed in high resolution mass spectrometry (HRMS) mode by using electro spray positive ionization. The parameters viz. desolvation gas $(500 \mathrm{~L} / \mathrm{h})$, cone gas $(25 \mathrm{~L} / \mathrm{h})$, desolvation temperature $\left(250^{\circ} \mathrm{C}\right)$, source temperature $\left(120^{\circ} \mathrm{C}\right)$, capillary voltage $(3000 \mathrm{~V})$, cone voltage $(30 \mathrm{~V})$ and collision energy $(10 \mathrm{~V})$ were used for HRMS analysis. All dilutions, mobile phase and other solutions were used for the analysis were filtered through $0.2 \mu$ nylon filter (Ultipor'N66 Nylon 6,6 membrane, Pall Sciences, Pall India Pvt. Ltd. Mumbai, India).

\section{Chemicals and reagent}

Armodafinil WS (working standard) was procured from APL Research Centre (A Division of Aurobindo Pharma Limited) Hyderabad, India as a gift sample. Formic acid and acetonitrile were procured from Merck Specialties Private Limited Mumbai, India. The mobile phase was the mixture of $0.1 \%$ aqueous formic acid and acetonitrile.

*Corresponding author: Pawan K Basniwal, Department of Pharmaceutical Chemistry, LBS College of Pharmacy, Jaipur -302004, Rajasthan, India, Tel: +919414788171; E-mail: pawanbasniwal@gmail.com

Received January 27, 2016; Accepted February 16, 2016; Published February 19,2016

Citation: Jain D, Basniwal PK (2016) Intrinsic Stability Study of Armodafinil Hydrochloride by Forced Degradation and Impurity Profiling. Pharm Anal Acta 7: 466 doi:10.4172/2153-2435.1000466

Copyright: (c) 2016 Jain D, et al. This is an open-access article distributed under the terms of the Creative Commons Attribution License, which permits unrestricted use, distribution, and reproduction in any medium, provided the original author and source are credited. 
Citation: Jain D, Basniwal PK (2016) Intrinsic Stability Study of Armodafinil Hydrochloride by Forced Degradation and Impurity Profiling. Pharm Anal Acta 7: 466. doi:10.4172/2153-2435.1000466

Page 2 of 18

\section{Sample preparation and chromatography}

Accurately weighed $10 \mathrm{mg}$ working AMD was dissolved in $5 \mathrm{ml}$ of acetonitrile and volume was made-up to $10 \mathrm{ml}$ by triple distilled water (stock P; $1000 \mu \mathrm{g} / \mathrm{ml}$ ). Aliquot of stock P was diluted with $50 \%$ acetonitrile to prepare stock Q $(100 \mu \mathrm{g} / \mathrm{ml})$ and it was used to prepare standard serial dilutions of AMD containing 5, 10, 15, 20 and $25 \mu \mathrm{g} / \mathrm{ml}$. All theses dilutions were filtered through $0.2 \mu$ nylon filter (Ultipor ${ }^{\circ} 66$ Nylon 6,6 membrane, Pall Sciences) and chromatographed by set of the conditions on Agilent Infinity 1260 series. The gradient mode of elution was used for separation by mixture of $0.1 \%$ formic acid and acetonitrile on Zorbax Eclipse Plus C18 column $(250 \times 4.6 \mathrm{~mm}, 5$ $\mu \mathrm{m})$ at $1 \mathrm{ml} / \mathrm{min}$ flow rate. AMD and all degradation products were successfully separated within $20 \mathrm{~min}$ and detection was performed by photodiode-array detector (PDA) at $252 \mathrm{~nm}$.

\section{Method validation}

The reliability of developed method was assured by establishing the validation parameters as per ICH guidelines $[9,10]$. The serial standard AMD dilutions $(5-25 \mu \mathrm{g} / \mathrm{ml})$ in $50 \%$ acetonitrile were used in triplicates for the linearity determination. The recovery method was adopted to assure the accuracy where the pre-analyzed samples were spiked with standard AMD dilutions and it was repeated six times. Repeatability and intermediate precision were studied for precision of the method. The six replicates of $10 \mu \mathrm{g} / \mathrm{ml}$ were chromatographed subsequently in a day to assure repeatability. Day-to-day analysis and analyst-to-analyst variation were performed for intermediate precision in the linearity range. The robustness of developed method was assured by the variation in temperature $\left(20,25\right.$ and $\left.30^{\circ} \mathrm{C}\right)$ during analysis and content of formic acid ( $0.1 \%)$ in aqueous phase variation by $5 \%$ change. The signal-to-noise ratio was used for limit of detection (LOD) and limit of quantitation (LOQ) of developed method for AMD. Analysis of degraded drug sample in stressed conditions was evidence for specificity of the method. Stability of AMD solution was demonstrated by analyzing six replicates of standard dilution $(10 \mu \mathrm{g} / \mathrm{ml})$ at different time intervals ( $0 \mathrm{~h}, 12 \mathrm{~h}, 24 \mathrm{~h}, 36 \mathrm{~h}$ and $48 \mathrm{~h})$.

\section{Forced degradation}

Forced hydrolytic degradation was performed in $50 \%$ acetonitrile $0.1 \mathrm{~N} \mathrm{HCl}, 50 \%$ alcoholic $0.1 \mathrm{~N} \mathrm{NaOH}$ and $50 \%$ aqueous acetonitrile by refluxing on water bath at $60^{\circ} \mathrm{C}$. The solid powder of drug in petridish was treated with $60^{\circ} \mathrm{C}$ in oven for thermal degradation and exposed to UV light for ten days for photolytic degradation. Oxidative degradation was performed in $10 \%$ hydrogen peroxide at room temperature.

\section{Forced degradation and impurity profiling}

Aliquot amount of above degraded sample was withdrawn at 24 hours interval after start of degradation. Degraded samples of acidic and alkaline conditions $(1 \mathrm{~mL})$ were withdrawn and neutralized by $0.1 \mathrm{~N} \mathrm{NaOH} / \mathrm{HCl}$. Degraded sample of thermal and photolytic conditions $(10 \mathrm{mg})$ were dissolved in solvents. Above all samples and samples of neutral hydrolytic and oxidative conditions were diluted to $100 \mu \mathrm{g} / \mathrm{mL}$. The solutions were filtered through $0.2 \mu$ nylon filter and chromatographed by developed method. The remaining percentage of AMD and degradation products at respective time was determined and degradation profiling of the drug was established. Standard AMD, neutralized and diluted samples of acidic and basic conditions, diluted samples of neutral hydrolytic were analyzed by Micromass Q-TOF micro (Waters) liquid chromatography-mass spectrometry (LC-MS) in HRMS mode to postulate the structure of the respective analytes.

\section{Results and Discussion}

\section{Method development}

The gradient mode (Table 1) was used for separation of drug and degradation products by mixture of $0.1 \%$ formic acid and acetonitrile on $\mathrm{C} 18$ column $(250 \times 4.6 \mathrm{~mm}, 5 \mu \mathrm{m})$ at $1 \mathrm{~mL} / \mathrm{min}$ flow rate. AMD and all degradation products were successfully separated within $20 \mathrm{~min}$ and detected PDA detector at $252 \mathrm{~nm}$ (Figure 1).

The AMD contains free amino group (amide) and it is soluble in acetonitrile and methanol; so $0.1 \%$ formic acid (mobile phase A) and acetonitrile (mobile phase $\mathrm{B}$ ) at $1 \mathrm{~mL} / \mathrm{min}$ was used for initial elution of the drug and its degraded products. Different combinations of $0.1 \%$ formic acid and acetonitrile were tried but there was no appropriate separation was found.

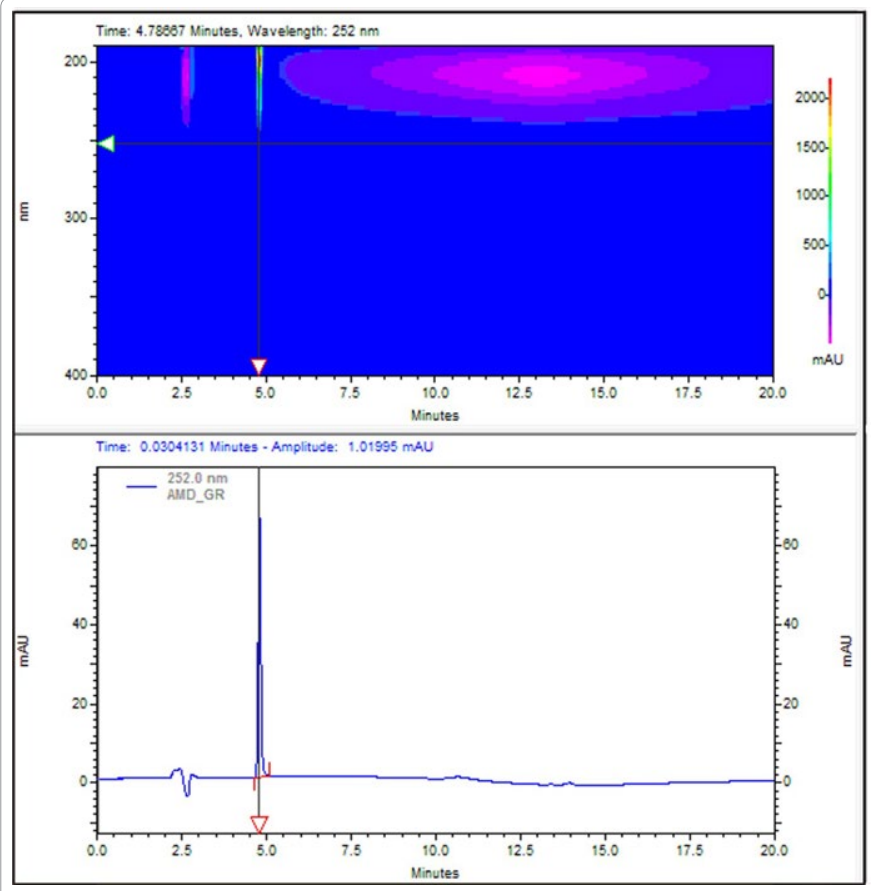

Figure 1: Counter plot and chromatogram of AMD in gradient mode of elution.

\begin{tabular}{|c|c|c|c|}
\hline Separation Variable & \multicolumn{3}{|l|}{ Value } \\
\hline Column & \multicolumn{3}{|c|}{$\begin{array}{l}\text { Zorbax Eclipse Plus C18 column } \\
(250 \times 4.6 \mathrm{~mm}, 5 \mu \mathrm{m})\end{array}$} \\
\hline Mobile phase & \multicolumn{3}{|c|}{$0.1 \%$ formic acid $(A)$ and Acetonitrile $(B)$} \\
\hline Diluent & \multicolumn{3}{|c|}{ Acetonitrile and water $(50: 50)$} \\
\hline Separation mode & \multicolumn{3}{|c|}{ Gradient mode } \\
\hline & Time & $0.1 \%$ formic acid $(\mathrm{A})$ & $\mathrm{ACN}(\mathrm{B})$ \\
\hline & $0 \min$ & $60 \%$ & $40 \%$ \\
\hline & $1 \mathrm{~min}$ & $60 \%$ & $40 \%$ \\
\hline & $10 \mathrm{~min}$ & $10 \%$ & $90 \%$ \\
\hline & $18 \mathrm{~min}$ & $60 \%$ & $40 \%$ \\
\hline & $20 \mathrm{~min}$ & $60 \%$ & $40 \%$ \\
\hline Flow rate & \multicolumn{3}{|c|}{$1.0 \mathrm{~mL} \mathrm{~min}{ }^{-1}$} \\
\hline Temperature & \multicolumn{3}{|l|}{ Ambient } \\
\hline Samples size & \multicolumn{3}{|l|}{$20 \mu \mathrm{L}$} \\
\hline Detection wavelength & \multicolumn{3}{|l|}{$252 \mathrm{~nm}$} \\
\hline Retention time & \multicolumn{3}{|c|}{$4.82 \mathrm{~min}$} \\
\hline
\end{tabular}

Table 1: Separation variable of RP-HPLC method for AMD. 
The gradient programming was designed for better separation as: $0-1 \mathrm{~min}, 25 \% \mathrm{~B}$; $1-10 \mathrm{~min}, 25-90 \% \mathrm{~B} ; 10-18 \mathrm{~min}, 90-25 \% \mathrm{~B} ; 18-20$ min, $25 \% \mathrm{~B}$. The drug and acid degraded product were well resolved with acceptable peak shape and symmetry but diluent peak was too high and one peak of degraded product was merged with drug peak in base degraded sample. The organic phase was increased to improve resolution but no significant difference was observed but RT of the degradation products were increased so again organic phase was increased as: $0-1 \mathrm{~min}, 50 \% \mathrm{~B}$; $1-10 \mathrm{~min}, 50-90 \% \mathrm{~B} ; 10-18 \mathrm{~min}, 90-50 \%$ B; $18-20 \mathrm{~min}, 50 \% \mathrm{~B}$. Most of the peaks were well separated but one DP was eluted near at diluents' peak; it was advised that organic phase should be lower and it was designed as: 0-1 min, 10\% B; 1-10 min, 10$90 \% \mathrm{~B} ; 10-18 \mathrm{~min}, 90-10 \% \mathrm{~B} ; 18-20 \mathrm{~min}, 10 \% \mathrm{~B}$. Again no significant difference was observed and finally the gradient was established as: $0-1$ min, $40 \%$ B; $1-10$ min, $40-90 \%$ B; $10-18$ min, $90-40 \%$ B; $18-20$ min, $40 \%$ $B$. Drug and all the degradation products formed in different forced conditions were well separated by this gradient programme (Table 1).

\section{Method validation}

System suitability parameters: The system performance consistency was assured by system suitability parameters, where six replicates of high quality control sample of AMD were injected, and column performances like tailing factor, retention time, and number of theoretical plates was observed (Figures 2 and 3 ).

The values of percentage of relative standard deviation (\% RSD) for these parameters were found within the acceptance criteria of system performance. AMD has better separation in set of conditions as the higher theoretical plates (55316) with a lower \% RSD (1.52). The tailing factor was found to be 0.444 with acceptable \% RSD. The capacity factor was 22.44 , i.e., AMD has sufficient opportunity to interact with the stationary phase resulting in differential migrations (Table 2).

The co-elution of impurities or degradants is generally investigated by examining the peak purity using a PDA detector (Figure 2). Threedimensional view (Figure 3 ) of the chromatogram has been confirmed that there was no peak around the AMD elution time. Here, the peak purity at $4.82 \mathrm{~min}$ was 1.0 ; there was no interference with elution of $\mathrm{AMD}$ at retention time, or nothing was co-eluting along with AMD at $4.82 \mathrm{~min}$. Thus, all system suitability parameters were found within the acceptance criteria.

Linearity, range and calibration: The linear regression equation was found to be $\mathrm{Y}=20313 \mathrm{x}+1687$ with correlation coefficient $\mathrm{r}^{2}=$ 0.999 and calibration graph was plotted for concentration versus area found in chromatogram (Table 2).

Accuracy: The recovery method was adopted to assure the accuracy, which was assured at all levels of linearity. It was found in between $98.97-100.33 \%$ by recovery method with $\%$ RSD of 0.63 ; which is very lower side (Table 2).

Precision: The precision of the developed method was performed under two heads: repeatability and intermediate precision. Repeatability was found in between $99.89-100.13 \%$, which was determined within same day with six replicates (Table 2). Intermediate precision was performed for both day-to-day (six different days) and analyst-toanalyst (six different analysts) variations which were observed as 99.99\% and $99.93 \%$. Reliability of the intermediate precision results was assured by lower \% RSD values (Table 2 ).

Robustness: The robustness of developed method was assured by the variation in temperature $\left(20,25\right.$ and $\left.30^{\circ} \mathrm{C}\right)$ during analysis and content of formic acid (0.1\%) in aqueous phase variation by $5 \%$ change. Robustness of the developed method was assured by two variables: formic acid percentage in aqueous content of mobile phase and temperature of analysis. Formic acid percentage was varied by $5 \%(0.105,0.100$ and $0.095 \%)$, while three levels $\left(20,25\right.$ and $\left.30^{\circ} \mathrm{C}\right)$ of temperature were used for robustness study. Both were found in between $99.60-100.10 \%$ and $99.80-100.10 \%$ at all concentration levels, respectively (Table 2$)$. The $\%$ RSD values were very less than unit $(0.21$ and 0.11$)$. Variation in percentage of formic acid (0.1\%) in aqueous content of mobile phase and temperature have no significant variation in results, thus developed method was robust.

LOD and LOQ: The limit of detection (LOD) and limit of quantitation (LOQ) were determined by signal-to-noise ratio. The mean LOD and LOQ were found to be $0.062 \mu \mathrm{g} / \mathrm{mL}$ and $0.206 \mu \mathrm{g} / \mathrm{mL}$ (Table 2), which show the sensitivity of the developed method.

Specificity: Analysis of degraded drug sample in stressed conditions was evidence for specificity of the method. The retention time, peak symmetry, peak purity and UV spectrum of the recorded chromatogram different samples were confirmed to assure the specificity. It was further supported by degradation profiling of the drug.

Stability of samples: The stability of AMD was assured during analysis by response ratio. It is ratio of peak area of drug in chromatogram to concentration of sample, which remains constant for a drug in set of conditions (developed method). The mean response ratio of six days was found to be 20523.83 with \% RSD of 1.57 (Table 2). Thus, drug was stable during analysis, i.e., without stress conditions.

\section{Forced degradation profiling}

Acidic degradation: AMD gets eluted at $4.82 \mathrm{~min}$ with acceptable resolution with all the degradation products of acidic degradation,

\begin{tabular}{|c|c|}
\hline Parameters & Values $^{\mathrm{a}}, \mathrm{SD}^{\mathrm{b}}, \% \mathrm{RSD}^{\mathrm{c}}$ \\
\hline System Suitability & - \\
\hline $\mathrm{RT}$ & $4.82 \pm 0.02,0.48$ \\
\hline No. of Theoretical Plates & $55316 \pm 842.61,1.52$ \\
\hline Tailing Factor & $0.444 \pm 0.01,1.48$ \\
\hline Peak purity & $1.00 \pm 0.00,0.00$ \\
\hline Capacity factor & $22.44 \pm 0.30,1.32$ \\
\hline Linearity & $5-25 \mu \mathrm{gmL}^{-1}$ \\
\hline Regression equation & $Y=20313 x+1687$ \\
\hline Correlation coefficient & 0.999 \\
\hline Accuracy & $99.88 \% \pm 0.63,0.63$ \\
\hline Precision & - \\
\hline Repeatability & $100.04 \% \pm 0.10,0.10$ \\
\hline \multicolumn{2}{|l|}{ Intermediate precision } \\
\hline Day-to-Day & $99.99 \% \pm 0.14,0.14$ \\
\hline Analyst-to-analyst & $99.93 \% \pm 0.10,0.10$ \\
\hline Response ratio & $20523.83 \pm 322.68,1.57$ \\
\hline LOQ & $0.206 \mu \mathrm{g} \mathrm{mL}^{-1} \pm 0.00,0.22$ \\
\hline LOD & $0.062 \mu \mathrm{g} \mathrm{mx} \pm 0.00,0.22$ \\
\hline Robustness & - \\
\hline $\begin{array}{c}\text { Formic acid }(0.1 \%) \text { in aqueous content } \\
\text { of mobile phase }\end{array}$ & $99.89 \% \pm 0.21,0.21$ \\
\hline Temperature $( \pm 5 \%)$ & $99.97 \% \pm 0.11,0.11$ \\
\hline Specificity & $\begin{array}{l}\text { Ascertained by analyzing standard drug } \\
\text { and forced degraded samples }\end{array}$ \\
\hline
\end{tabular}

$a=$ mean of six replicates; $b=$ standard deviation; $c=$ percent relative standard deviation

Table 2: Validation parameters for AMD 


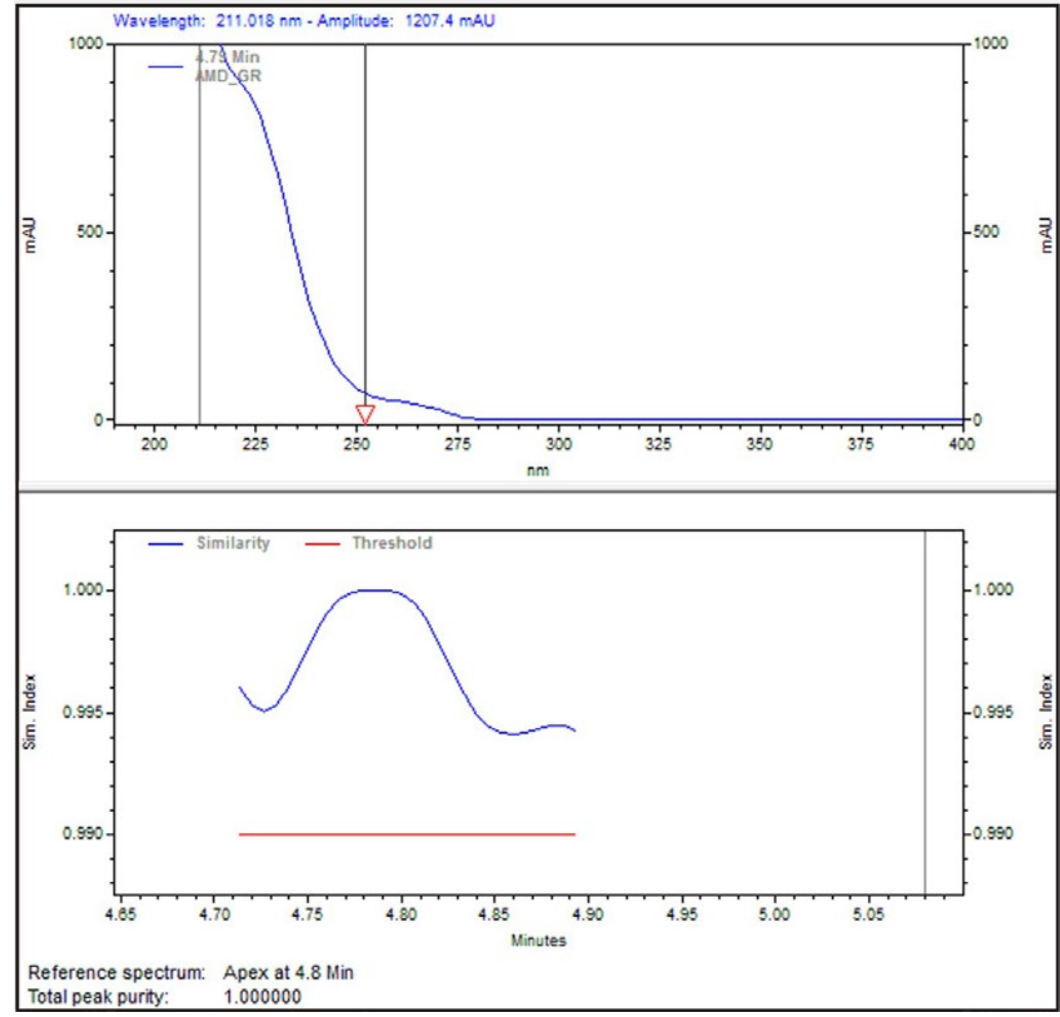

Figure 2: Gaussian spectrum and peak purity of AMD at $4.8 \mathrm{~min}$ in gradient mode.

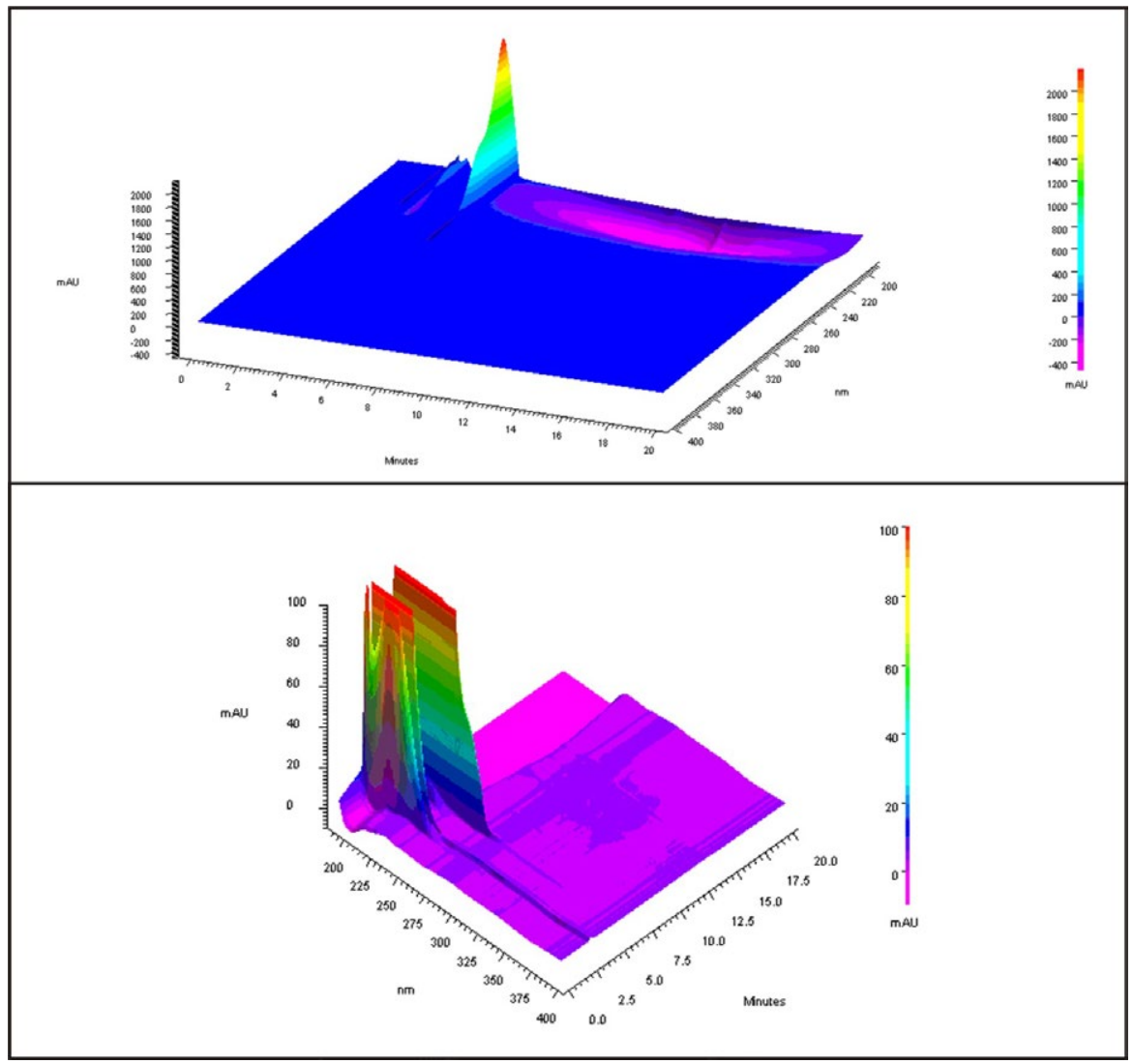

Figure 3: 3D view of chromatogram of AMD. 
Citation: Jain D, Basniwal PK (2016) Intrinsic Stability Study of Armodafinil Hydrochloride by Forced Degradation and Impurity Profiling. Pharm Anal Acta 7: 466. doi:10.4172/2153-2435.1000466

Page 5 of 18

when it was performed in $50 \%$ acetonitrile $0.1 \mathrm{~N} \mathrm{HCl}$ at $60^{\circ} \mathrm{C}$ (Figure 4). The drug gets completely degraded within five days as no peak was found at $4.82 \mathrm{~min}$ on $5^{\text {th }}$ day. Total eleven degradation products (DPs) have been formed in acidic degradation and seven degradation products appeared on first day, viz. AMD1 (7.24 min), AMD3 (8.64 min), AMD5 (10.03 min), AMD6 (10.58 min) AMD7 (10.92 min) and AMD9 (12.50 min) (Figure 4).

Four degradation products AMD2 (7.68 min), AMD8 (12.02 min), AMD10 (13.33 min) and AMD11 (13.87 min) were observed on later days. On first day, major degradation product was AMD6 (10.58 min), which decreases with time and another two major DPs, AMD4 (9.21 min) and AMD5 (10.03 min) were increased with time. Remaining other DPs were also increased with time but their concentration is not significant as compared to AMD6 (Table 3 and Figure 5).

Alkaline degradation: There was no peak found at $4.82 \mathrm{~min}$ of AMD on fourth day of alkaline degradation, when it was performed in $0.1 \mathrm{~N} \mathrm{NaOH}$ (methanolic) at $60^{\circ} \mathrm{C}$ (Figure 6). Total seven degradation products were found as AMD12 (5.73 min), AMD13 (6.98 min), AMD3 (8.64 min), AMD4 (9.21 min), AMD5 (10.03 min), AMD6 (10.58 min) and AMD10 (13.33 min)

Most of drug was degraded on the first day as drug has amide functional group which was hydrolyzed in alkaline conditions. AMD6 was major degradation product as similar in acidic condition, which was further degraded with the time. AMD12 (5.73) and AMD3 (8.64 $\mathrm{min}$ ) are another two major DPs, their concentrations were increased with time. AMD13 (6.98 min) and AMD10 (13.3 min) were appeared on forth and third day respectively which were in low concentration (Table 4 and Figure 7).

Neutral degradation: Total seven degradation products were formed in neutral condition, when it was performed in $50 \%$ acetonitrile at $60^{\circ} \mathrm{C}$ (Figure 8). AMD14 (3.39 min) was new degradation product in neutral condition and appeared on $5^{\text {th }}$ day. AMD6 (10.58 $\mathrm{min}$ ) was major degradation product which was further degraded with time. Both drug AMD and AMD6 were degraded in similar fashion with the time.

AMD3 (8.64 min) was increased with time while another DPs AMD14, AMD4 and AMD11 have zig-zag pattern of concentration with time. AMD12 was increased first and followed by decrease in concentration with time (Table 5 and Figure 9). Thus, AMD drug was extensively degraded in alkaline condition followed by acidic and neutral condition. Four DPs vis. AMD3, AMD4, AMD5 and AMD6 were observed in all the conditions.

Thermal, oxidative and photolytic degradation: RP-HPLC analysis of stressed samples of AMD in thermal, oxidative and photolytic degradation has shown that there was no degradation in these conditions.

Thus, forced degradation profiling of AMD has shown that the drug was extensively degraded in basic condition followed by acidic and neutral condition (Figure 10). Four DPs vis. AMD3, AMD4, AMD5 and AMD6 were observed in all the conditions.

\section{Degradation pathway and impurity profiling}

Standard drug AMD: All the LC-MS studies were performed in positive mode using leucine enkephalin as standard for HRMS analysis. AMD and an impurity of AMD (AMD-Imp) were observed at RRT of 0.53 and 1.00 during TOF MS ES+ scanning (Figure 11).
The ESI mass spectrum of AMD showed protonated molecular ion $[\mathrm{M}+\mathrm{H}]^{+}$at $\mathrm{m} / \mathrm{z} 274.0828$ and ppm errors in mass was -1.83 . Sodium adduct of drug was observed $[\mathrm{M}+\mathrm{Na}+\mathrm{H}]^{+}$at $\mathrm{m} / \mathrm{z} 296.0721$ without error from exact mass of sodium adduct of the drug (Table 6 and Figure 12). It was also advocated by its MS-MS fragmentation pattern which was observed as $273.0823 \rightarrow 167.0855$ (Figure 13).

An impurity was eluted before the drug $(\mathrm{RRT}=0.53)$ (Figure 11), which shows ESI mass spectrum of protonated molecular ion [M

\begin{tabular}{|c|c|c|c|c|c|c|}
\hline \multirow{2}{*}{$\begin{array}{c}\text { Days } \rightarrow \\
\text { Analytes } \\
(\text { RT in min) } \downarrow\end{array}$} & \multicolumn{6}{|c|}{ Area at different $\mathrm{RT}( \pm 0.1 \mathrm{~min})$} \\
\hline & Standard & 1 & 2 & 3 & 4 & 5 \\
\hline AMD (4.82) & 2038400 & 742012 & 304323 & 103952 & 53074 & - \\
\hline AMD1 (7.24) & - & 5967 & 11202 & 20315 & 27075 & 29673 \\
\hline AMD2 (7.68) & - & - & - & 4590 & 6583 & 7563 \\
\hline AMD3 (8.64) & - & 12842 & 32947 & 45646 & 53282 & 63022 \\
\hline AMD4 (9.21) & - & 43929 & 86754 & 157372 & 207402 & 277458 \\
\hline AMD5 (10.03) & - & 53720 & 73634 & 94629 & 132283 & 168643 \\
\hline AMD6 (10.58) & - & 1756349 & 1607462 & 1410479 & 1274421 & 1123813 \\
\hline AMD7 (10.92) & - & 8533 & 16553 & 20274 & 24693 & 28456 \\
\hline AMD8 (12.02) & - & - & 5634 & 7865 & 11802 & 14325 \\
\hline AMD9 (12.50) & - & 12645 & 19355 & 27463 & 37227 & 45382 \\
\hline $\begin{array}{l}\text { AMD10 } \\
(13.33)\end{array}$ & - & - & - & - & 5277 & 6453 \\
\hline $\begin{array}{l}\text { AMD11 } \\
(13.87)\end{array}$ & - & - & - & 4785 & 8247 & 12237 \\
\hline
\end{tabular}

$\mathrm{RT}=$ Retention Time in Minute

Table 3: Result of acidic degradation of AMD.

\begin{tabular}{|c|c|c|c|c|c|c|c|c|}
\hline \multirow{2}{*}{$\begin{array}{c}\text { Days } \downarrow \\
\text { Analyte } \\
\text { (RT in } \\
\text { min) } \rightarrow\end{array}$} & \multicolumn{8}{|c|}{ Area at different $\mathrm{RT}( \pm 0.1 \mathrm{~min})$} \\
\hline & $\begin{array}{l}\text { AMD } \\
(4.82)\end{array}$ & $\begin{array}{c}\text { AMD } 12 \\
(5.73)\end{array}$ & $\begin{array}{c}\text { AMD13 } \\
(6.98)\end{array}$ & $\begin{array}{l}\text { AMD3 } \\
(8.64)\end{array}$ & $\begin{array}{l}\text { AMD4 } \\
(9.21)\end{array}$ & \begin{tabular}{|l|} 
AMD5 \\
$(10.03)$
\end{tabular} & $\begin{array}{l}\text { AMD6 } \\
\text { (10.58) }\end{array}$ & $\begin{array}{l}\text { AMD10 } \\
(13.33)\end{array}$ \\
\hline Standard & 2038400 & - & - & - & - & - & - & - \\
\hline 1 & 505332 & 15372 & - & 12839 & 4528 & 4448 & 1856349 & - \\
\hline 2 & 147232 & 49221 & - & 22385 & 5639 & 5173 & 1640234 & - \\
\hline 3 & 31594 & 119293 & - & 43752 & 8462 & 5349 & 1452031 & 5642 \\
\hline 4 & & 157396 & 4200 & 62943 & 11934 & 9472 & 1305032 & 7325 \\
\hline 5 & & 273722 & 5723 & 74556 & 15770 & 16783 & 1046241 & 9462 \\
\hline
\end{tabular}

$\mathrm{RT}=$ Retention Time in Minute

Table 4: Result of alkaline degradation of AMD.

\begin{tabular}{|c|c|c|c|c|c|c|c|c|}
\hline $\begin{array}{c}\text { Days } \downarrow \\
\text { Analyte } \\
\left(\begin{array}{c}\text { RT in } \\
\text { min }) \rightarrow\end{array}\right.\end{array}$ & $\begin{array}{c}\text { AMD14 } \\
(3.39)\end{array}$ & $\begin{array}{c}\text { AMD } \\
(4.82)\end{array}$ & $\begin{array}{c}\text { ADM12 } \\
(5.73)\end{array}$ & $\begin{array}{c}\text { AMD3 } \\
(8.64)\end{array}$ & $\begin{array}{c}\text { AMD4 } \\
(9.21)\end{array}$ & $\begin{array}{c}\text { AMD5 } \\
(10.03)\end{array}$ & $\begin{array}{c}\text { AMD6 } \\
(10.58)\end{array}$ & $\begin{array}{c}\text { AMD11 } \\
(13.87)\end{array}$ \\
\hline STD & - & 2038400 & - & - & - & - & - & - \\
\hline 1 & - & 1745242 & 16342 & 37294 & 4546 & 7543 & 1835263 & - \\
\hline 2 & - & 1562947 & 31201 & 64721 & 5846 & 10283 & 1756342 & - \\
\hline 3 & - & 1462005 & 53621 & 101023 & 8930 & 15832 & 1563483 & - \\
\hline 4 & - & 1372981 & 73621 & 156323 & 12640 & 23711 & 1378532 & - \\
\hline 5 & 3664 & 1193721 & 105702 & 187754 & 16348 & 29120 & 1202136 & - \\
\hline 6 & 4274 & 954770 & 143719 & 217298 & 17436 & 34295 & 934653 & - \\
\hline 7 & 4628 & 748393 & 103422 & 254712 & 19563 & 22947 & 746522 & 4239 \\
\hline 8 & 3642 & 532053 & 73532 & 278203 & 10278 & 15482 & 583926 & 5422 \\
\hline 9 & 7473 & 214849 & 52813 & 320120 & 16425 & 25632 & 463202 & 6652 \\
\hline 10 & 5362 & 110387 & 43521 & 356206 & 12037 & 32192 & 294723 & 3542 \\
\hline
\end{tabular}

$\mathrm{RT}=$ Retention Time in Minute

Table 5: Result of neutral degradation of AMD 


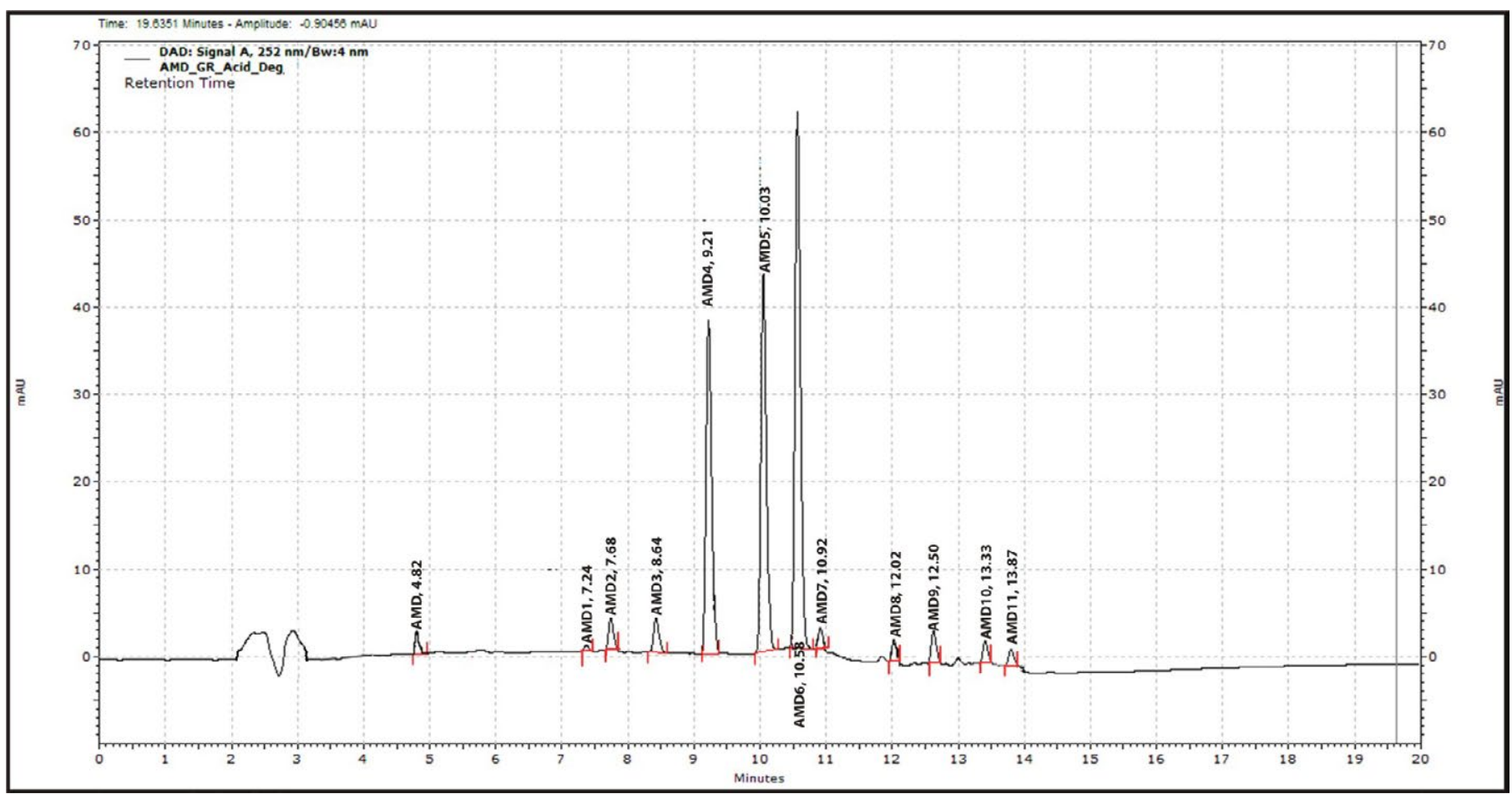

Figure 4: Representative chromatogram of AMD in acidic condition.

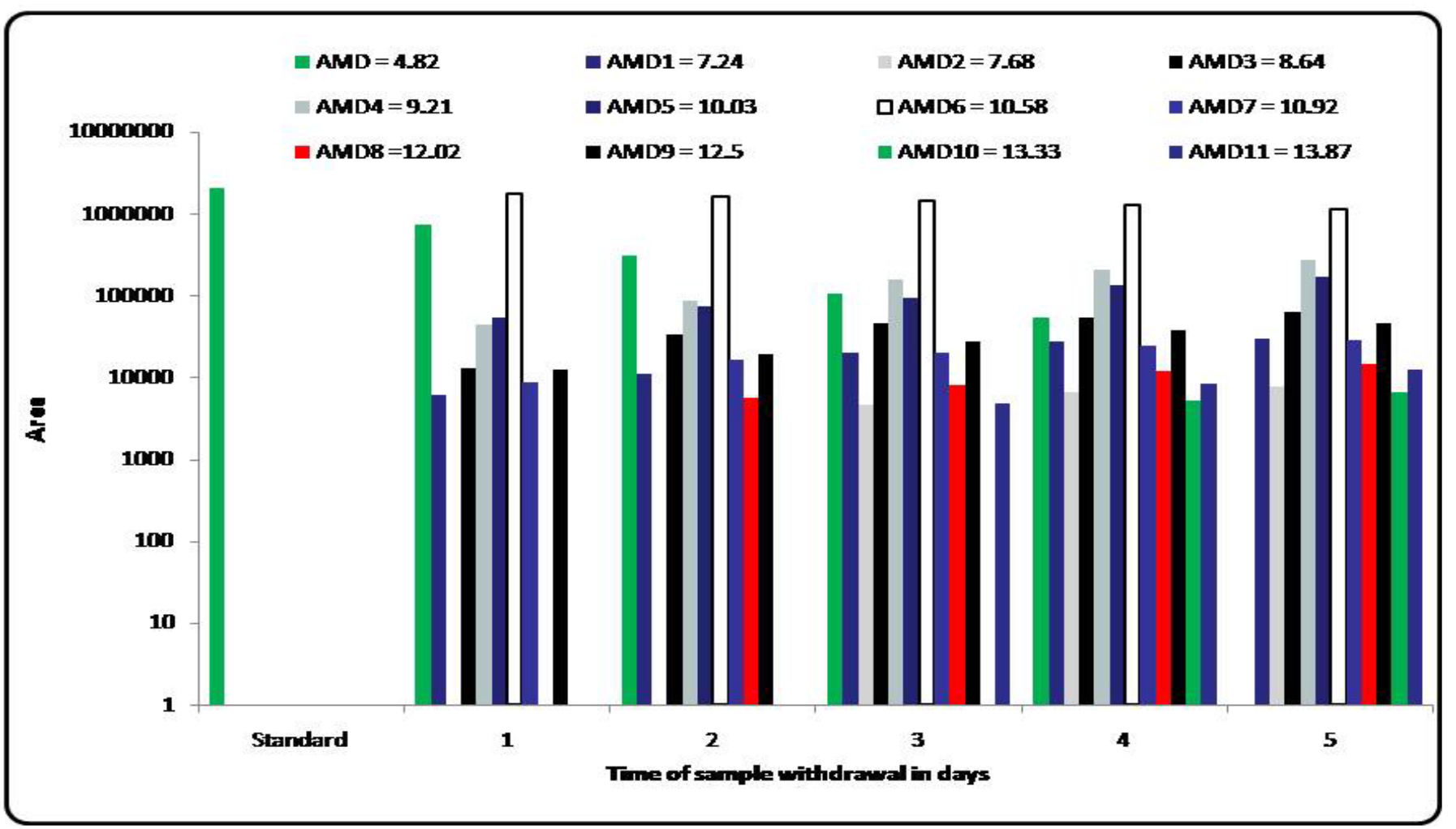

Figure 5: Bar graph with logarithmic scale for degradation of AMD in acidic condition. 


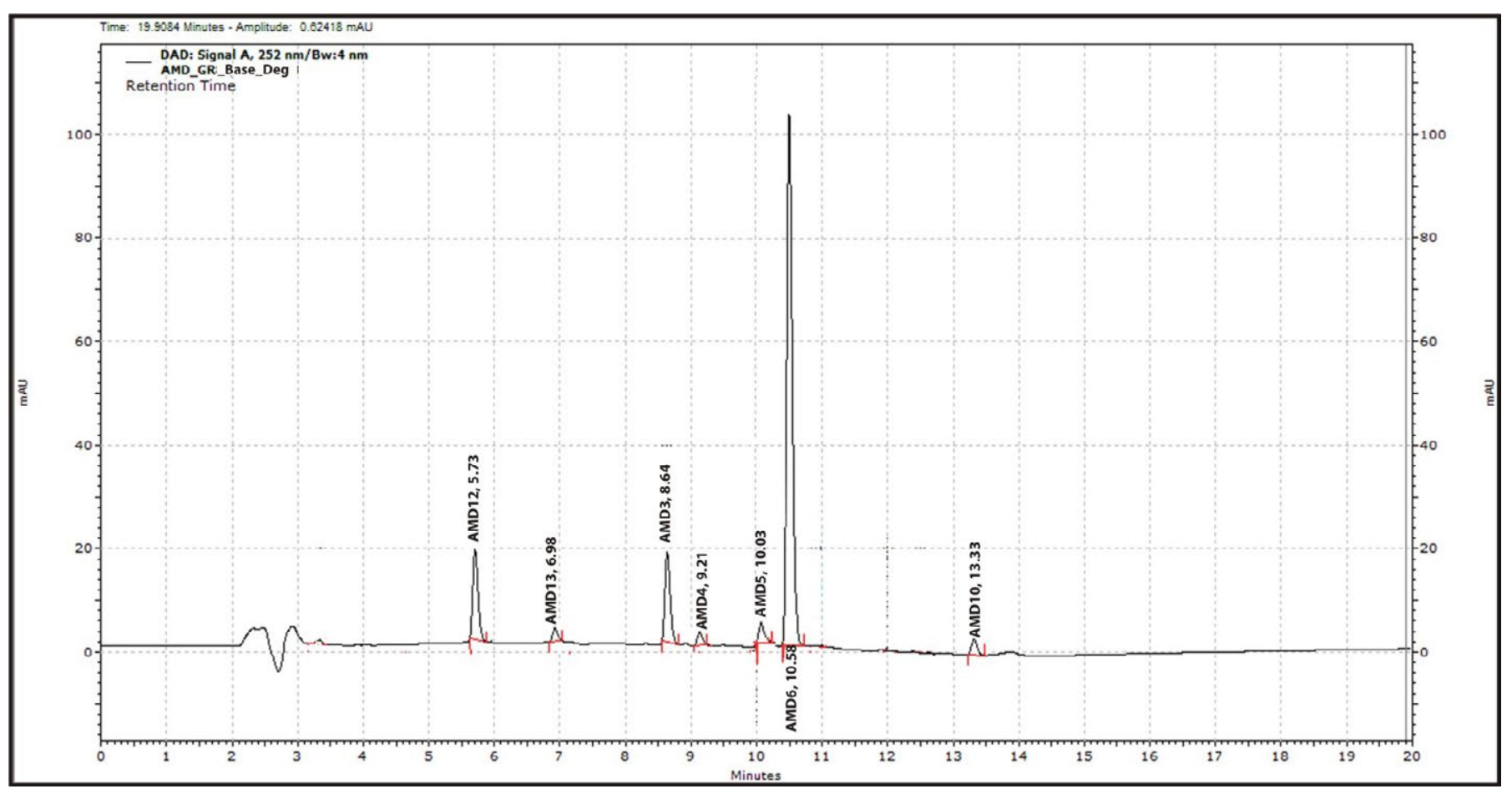

Figure 6: Representative chromatogram of AMD in alkaline condition.

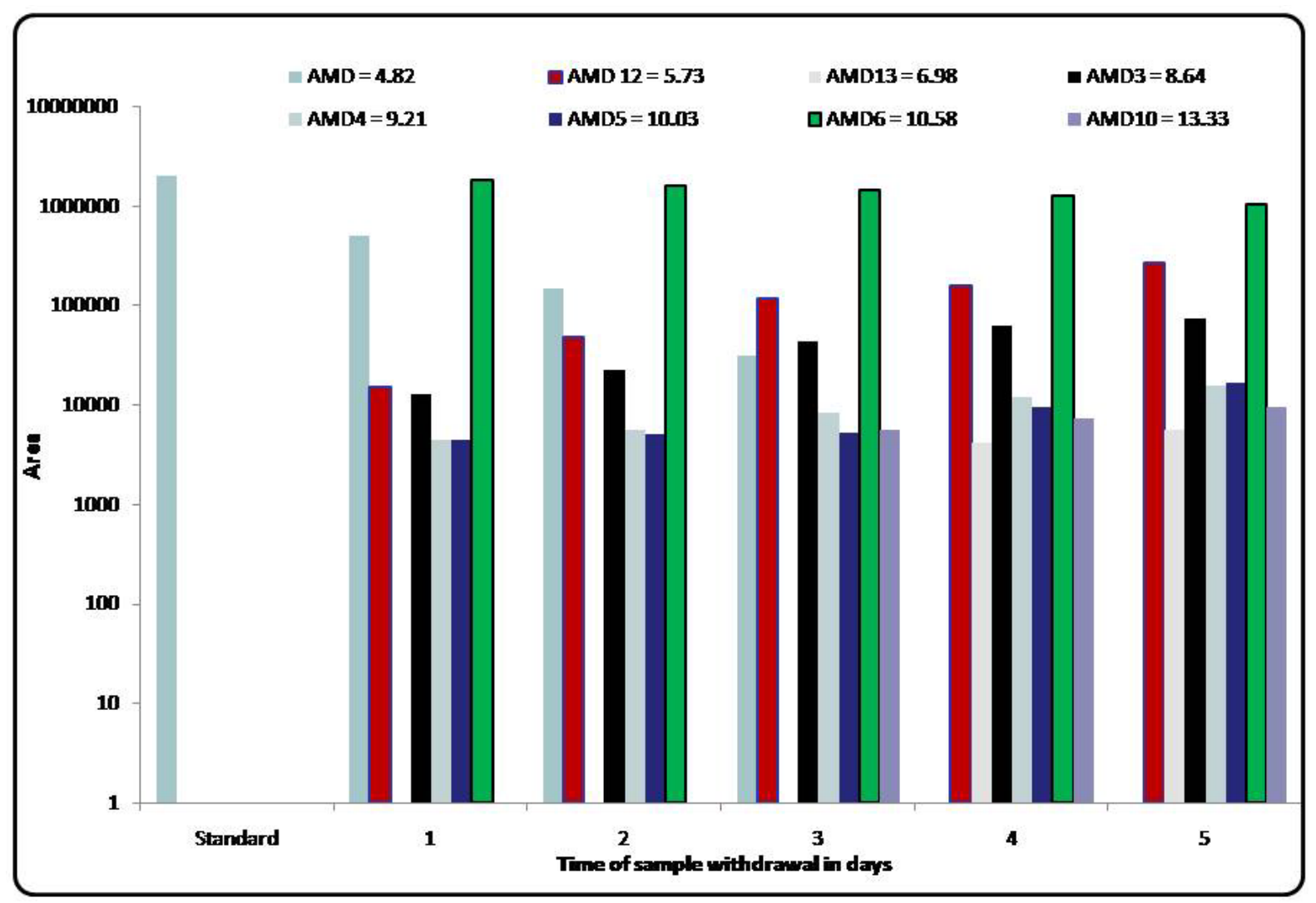

Figure 7: Bar graph with logarithmic scale for degradation of AMD in alkaline condition. 


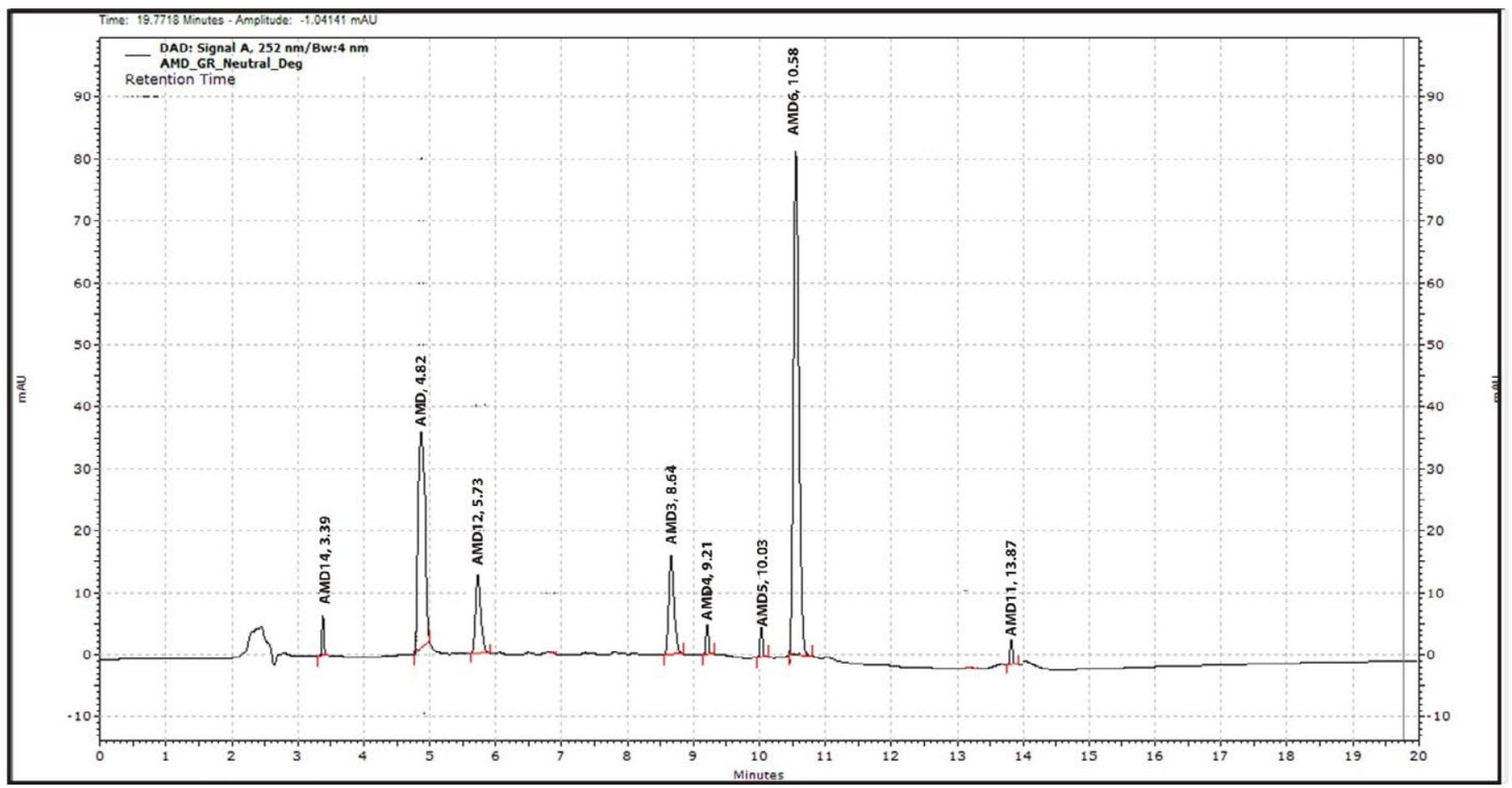

Figure 8: Representative chromatogram of AMD in neutral condition.

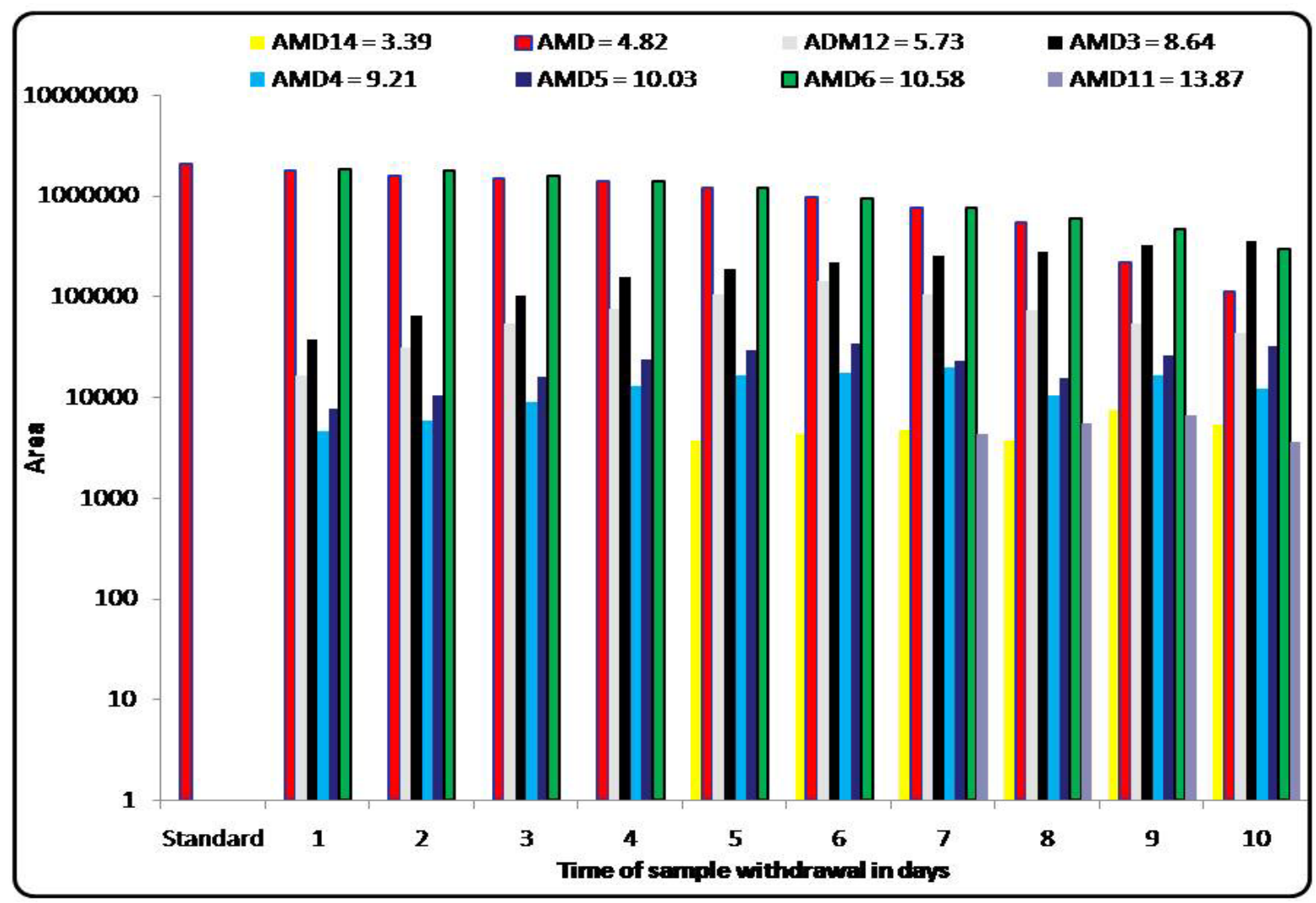

Figure 9: Bar graph with logarithmic scale for degradation of AMD in neutral condition. 


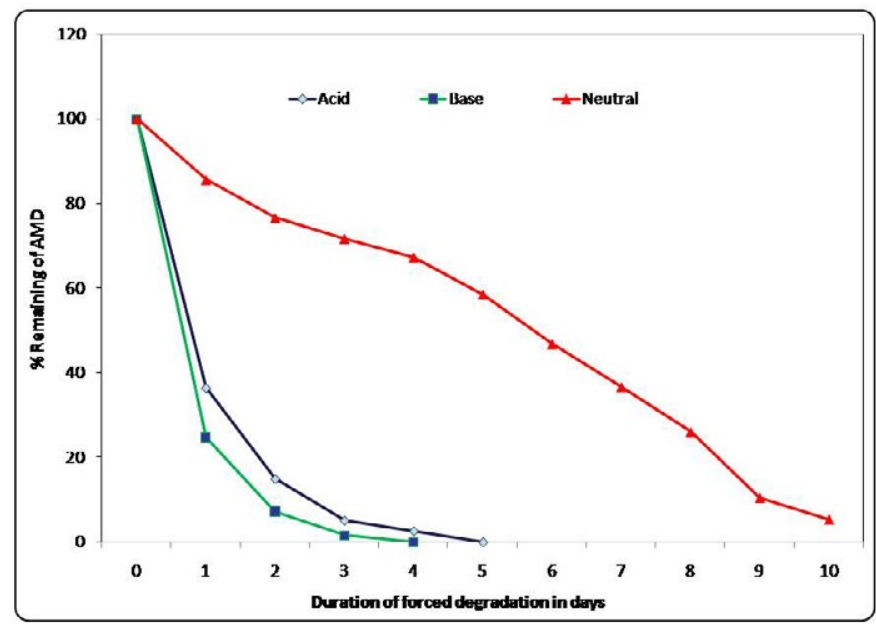

Figure 10: Forced degradation profiling of AMD in acidic, alkaline and neutral condition.

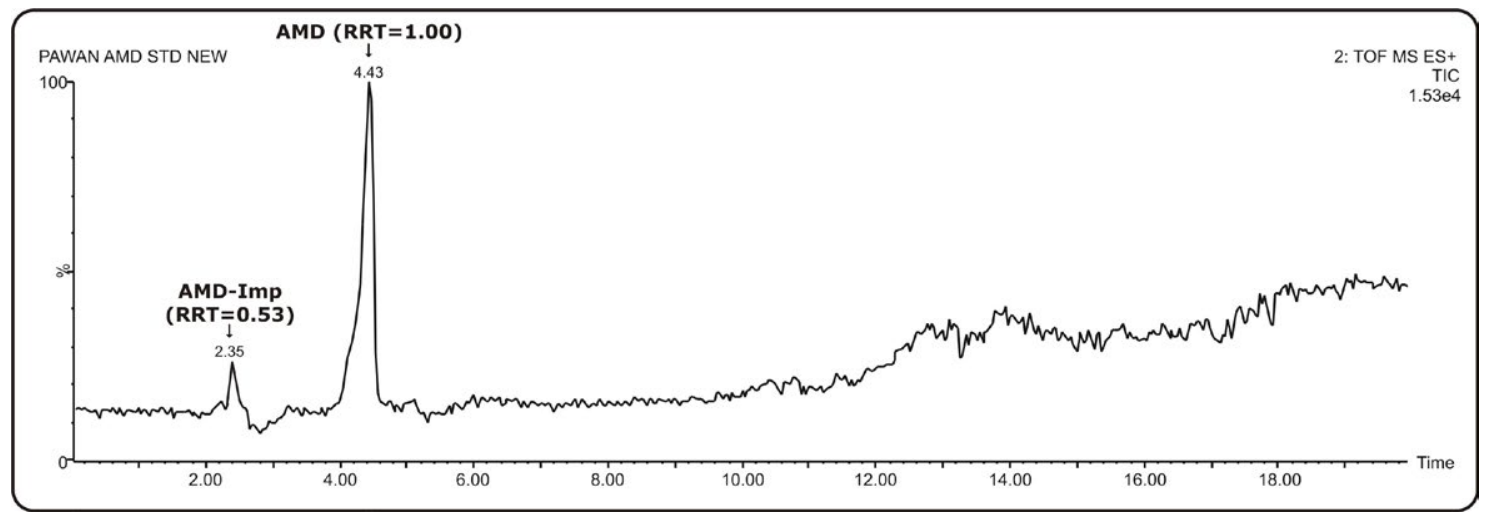

Figure 11: Chromatogram of standard AMD by TOF MS ES+ scanning.

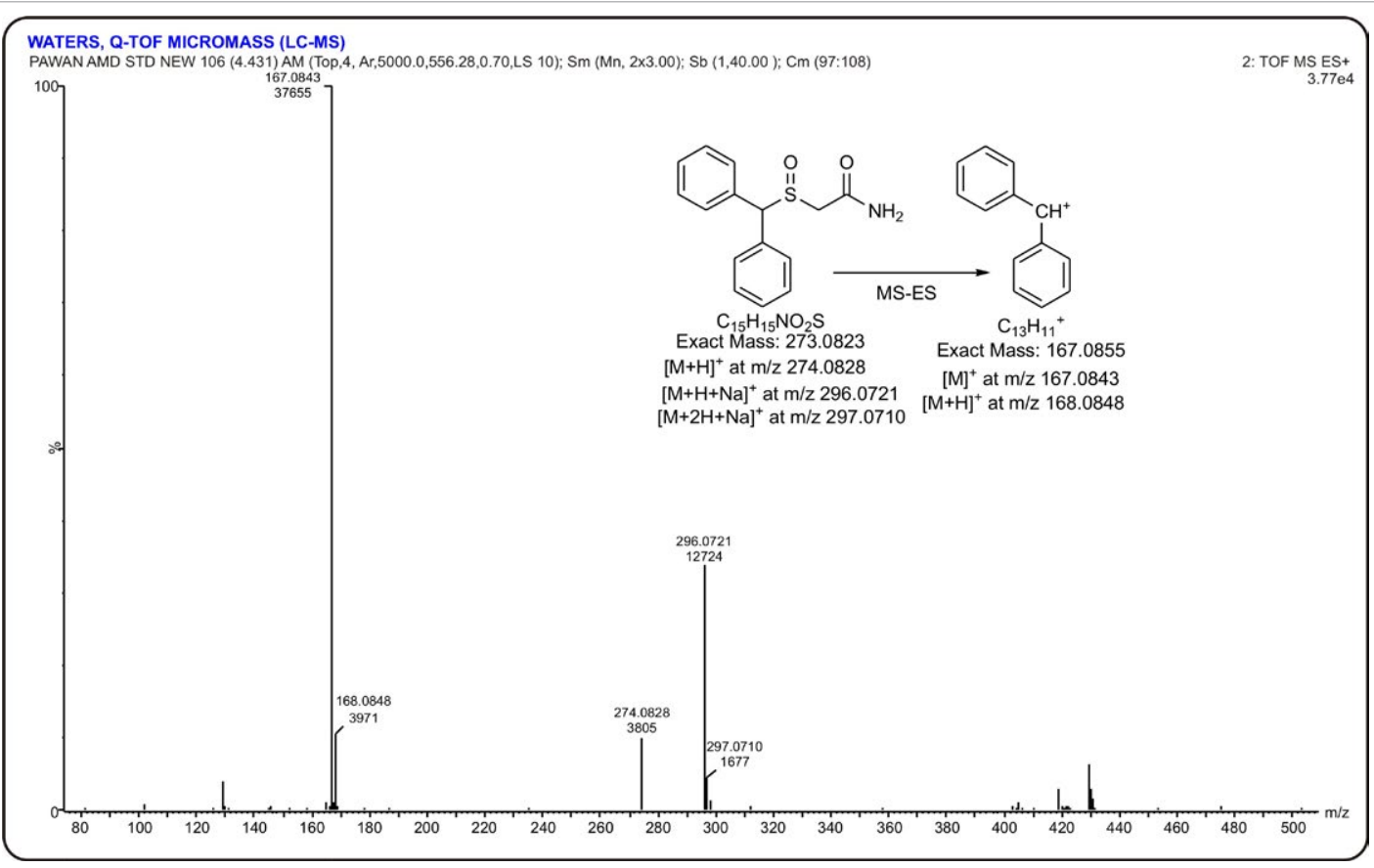

Figure 12: TOF MS-ES+ spectrum and proposed fragmentation pattern of AMD in standard AMD. 
Citation: Jain D, Basniwal PK (2016) Intrinsic Stability Study of Armodafinil Hydrochloride by Forced Degradation and Impurity Profiling. Pharm Anal Acta 7: 466. doi:10.4172/2153-2435.1000466

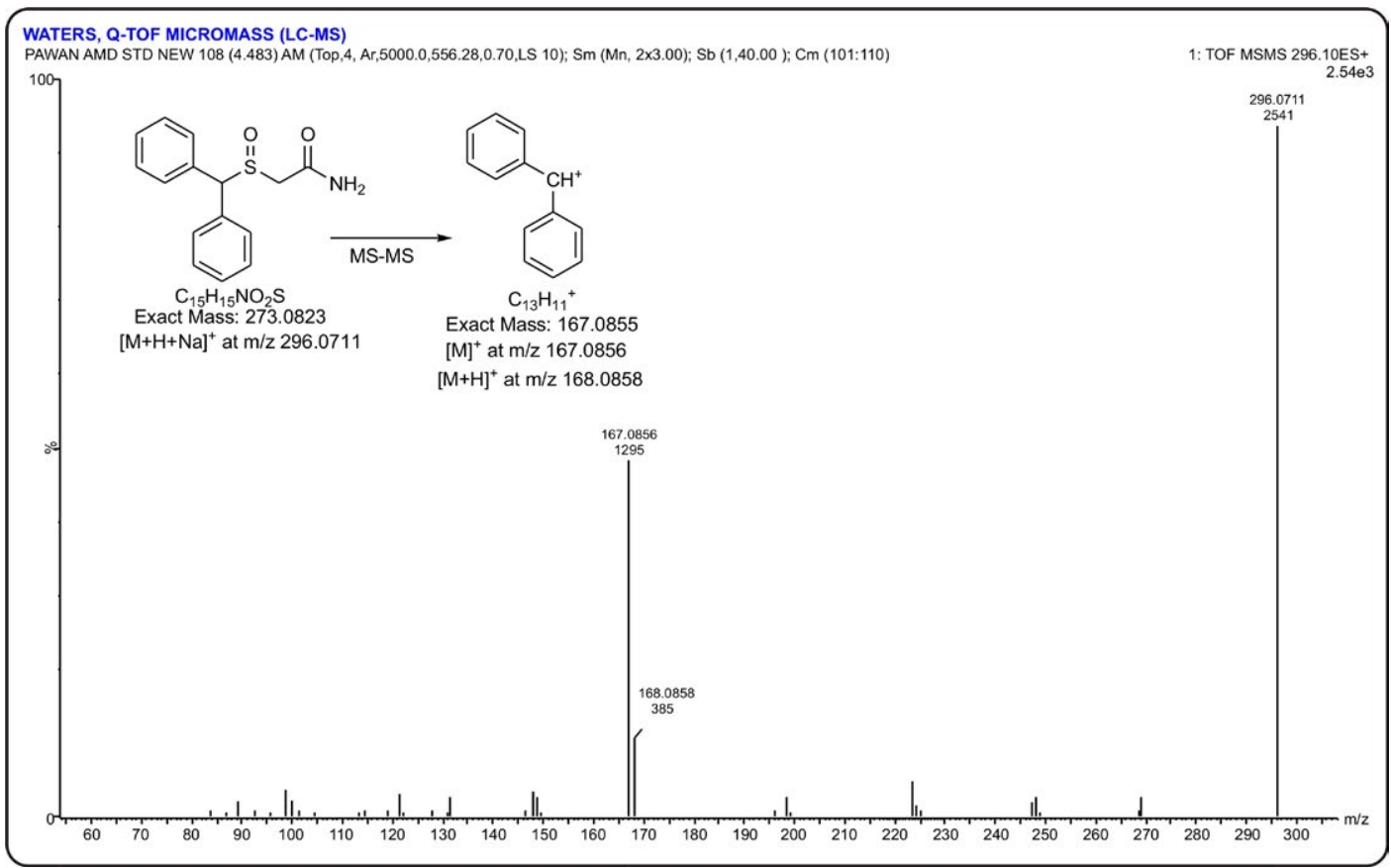

Figure 13: TOF MS-MS spectrum and proposed fragmentation pattern of AMD in standard AMD.

\begin{tabular}{|c|c|c|c|c|c|c|c|}
\hline Analyte & $\begin{array}{l}\text { RRT in LC } \\
\text { MS }\end{array}$ & $\begin{array}{l}\text { MS-ES or } \\
\text { MS-MS }\end{array}$ & $\mathrm{m} / \mathrm{z}$ value & Measured Mass & $\begin{array}{c}\text { Best possible molecular } \\
\text { formulae }\end{array}$ & Exact Mass & PPM error \\
\hline \multirow[t]{2}{*}{ AMD-Imp } & 0.53 & MS-ES & 157.0247 & 156.0247 & $\mathrm{C}_{7} \mathrm{H}_{8} \mathrm{O}_{2} \mathrm{~S}$ & 156.0245 & -1.28 \\
\hline & & & 125.0346 & 124.0346 & $\mathrm{C}_{7} \mathrm{H}_{8} \mathrm{~S}$ & 124.0347 & 0.81 \\
\hline \multirow[t]{8}{*}{ AMD } & 1.00 & MS-ES & 296.0721 & 273.0823 & $\mathrm{C}_{15} \mathrm{H}_{15} \mathrm{NO}_{2} \mathrm{~S}$ & 273.0823 & 0.00 \\
\hline & & & 297.0710 & 273.0812 & $\mathrm{C}_{15} \mathrm{H}_{15} \mathrm{NO}_{2} \mathrm{~S}$ & 273.0823 & 4.03 \\
\hline & & & 274.0828 & 273.0828 & $\mathrm{C}_{15} \mathrm{H}_{15} \mathrm{NO}_{2} \mathrm{~S}$ & 273.0823 & -1.83 \\
\hline & & & 167.0843 & 167.0843 & $\mathrm{C}_{13} \mathrm{H}_{11}^{+}$ & 167.0855 & 7.18 \\
\hline & & & 168.0848 & 167.0848 & $\mathrm{C}_{13} \mathrm{H}_{11}{ }^{+}$ & 167.0855 & 4.19 \\
\hline & 1.00 & MS-MS & 296.0711 & 273.0813 & $\mathrm{C}_{15} \mathrm{H}_{15} \mathrm{NO}_{2} \mathrm{~S}$ & 273.0823 & 3.66 \\
\hline & & & 167.0856 & 167.0856 & $\mathrm{C}_{13} \mathrm{H}_{11}{ }^{+}$ & 167.0855 & -0.60 \\
\hline & & & 168.0858 & 167.0858 & $\mathrm{C}_{13} \mathrm{H}_{11}{ }^{+}$ & 167.0855 & -1.80 \\
\hline
\end{tabular}

Table 6: Observed $\mathrm{m} / \mathrm{z}$ values for the $[\mathrm{M}+\mathrm{H}]^{+}$ions and major fragments of AMD and its impurity in drug.

$+\mathrm{H}]^{+}$at $\mathrm{m} / \mathrm{z} 157.0247$ and it is postulated as phenylmethanesulfinic acid. It was further fragmented into phenyl-methanethiol, which mass abundance $[\mathrm{M}+\mathrm{H}]^{+}$was at $\mathrm{m} / \mathrm{z} 125.0346$ (Figure 14 and Table 6).

Acidic degradation: Three major degradation products have been observed in acidic degradation of the drug during HRMS analysis and designated as: AMD1, AMD6 and AMD14. These were eluted at RRT of $1.49,2.17$ and 0.69 , respectively (Figure 15 ).

Methylsulfinyl diphenylmethane was identified as AMD14 which mass abundance $[\mathrm{M}+\mathrm{H}]^{+}$was at $\mathrm{m} / \mathrm{z}$ 231.0760. It was further supported by its daughter ion of diphenyl methane abundance $[\mathrm{M}+$ $\mathrm{H}]^{+}$at $\mathrm{m} / \mathrm{z} 167.0860$ (Table 7 and Figure 16).

AMD $($ RRT $=1.00)$ has shown three fragmented products $(167.0855,156.0245$ and 125.0147) with small ppm error in mass (Table 7). The possible structures of these fragmented products were recommended as shown in Figure 17.

AMD1 was formed by removal of amino group from the AMD drug and indentified as 2-(benzhydrylsulfinyl) acetaldehyde and its protonated molecular ion $[\mathrm{M}+\mathrm{H}]^{+}$was observed at $\mathrm{m} / \mathrm{z} 259.0721$. It was further recommended by its daughter products as: $258.0715 \rightarrow$ $246.0715 \rightarrow 156.0245$ (Figure 18) and the ppm error in mass was less than 5 for most of daughter products (Table 7). It was also shown as prominent peak of diphenyl methyl ion at m/z 167.0850 which is common to AMD (Figures 17 and 18).

Diphenyl-methanesulfinic acid was identified as AMD6 which mass abundance $[\mathrm{M}+\mathrm{H}]^{+}$was at $\mathrm{m} / \mathrm{z} 232.0560$ (Figure 19). It was further fragmented into two different products viz. diphenylmethyl ion and phenylmethanethiol with mass abundance $[\mathrm{M}+\mathrm{H}]^{+}$at $\mathrm{m} / \mathrm{z}$ 167.0851 and 125.0341, respectively; with less than 5 ppm error in mass (Table 7).

Alkaline degradation: Two degradation products were recognized by TOF MS ES+ scanning at RRT of 2.47 and 1.20 during HRMS analysis of alkaline degraded samples and designated as carboxylic acid (AMD8) and its sodium salt (AMD12), respectively (Figure 20).

AMD12 is sodium salt of hydrolysed AMD, which protonated molecular ion $[\mathrm{M}+\mathrm{H}]^{+}$was observed at $\mathrm{m} / \mathrm{z} 297.0492$ and recognized 
Citation: Jain D, Basniwal PK (2016) Intrinsic Stability Study of Armodafinil Hydrochloride by Forced Degradation and Impurity Profiling. Pharm Anal Acta 7: 466. doi:10.4172/2153-2435.1000466

Page 11 of 18

\begin{tabular}{|c|c|c|c|c|c|c|c|}
\hline Analyte Code & $\begin{array}{l}\text { RRT in LC } \\
\text { MS }\end{array}$ & $\begin{array}{l}\text { MS-ES or } \\
\text { MS-MS }\end{array}$ & $\mathrm{m} / \mathrm{z}$ value & Measured Mass & $\begin{array}{l}\text { Best possible molecular } \\
\text { formulae }\end{array}$ & Exact Mass & PPM error \\
\hline \multirow[t]{3}{*}{ AMD14 } & 0.69 & MS-ES & 231.0760 & 230.0760 & $\mathrm{C}_{14} \mathrm{H}_{14} \mathrm{OS}$ & 230.0765 & 2.17 \\
\hline & & & 167.0860 & 167.0860 & $\mathrm{C}_{13} \mathrm{H}_{11}{ }^{+}$ & 167.0855 & -2.99 \\
\hline & & & 168.0868 & 167.0868 & $\mathrm{C}_{13} \mathrm{H}_{11}{ }^{+}$ & 167.0855 & -7.78 \\
\hline \multirow[t]{5}{*}{ AMD } & 1.00 & MS-ES & 296.0729 & 273.0831 & $\mathrm{C}_{15} \mathrm{H}_{15} \mathrm{NO}_{2} \mathrm{~S}$ & 273.0823 & -2.93 \\
\hline & & & 167.0852 & 167.0852 & $\mathrm{C}_{13} \mathrm{H}_{11}^{+}$ & 167.0855 & 1.80 \\
\hline & & & 168.0843 & 167.0843 & $\mathrm{C}_{13} \mathrm{H}_{11}{ }^{+}$ & 167.0855 & 7.18 \\
\hline & & & 157.0249 & 156.0249 & $\mathrm{C}_{7} \mathrm{H}_{8} \mathrm{O}_{2} \mathrm{~S}$ & 156.0245 & -2.56 \\
\hline & & & 126.0143 & 125.0143 & $\mathrm{C}_{2} \mathrm{H}_{7} \mathrm{NO}_{3} \mathrm{~S}$ & 125.0147 & 3.20 \\
\hline \multirow[t]{5}{*}{ AMD1 } & 1.49 & MS-ES & 259.0721 & 258.0721 & $\mathrm{C}_{15} \mathrm{H}_{14} \mathrm{O}_{2} \mathrm{~S}$ & 258.0715 & -2.32 \\
\hline & & & 247.0719 & 246.0719 & $\mathrm{C}_{14} \mathrm{H}_{14} \mathrm{O}_{2} \mathrm{~S}$ & 246.0715 & -1.63 \\
\hline & & & 167.0850 & 167.0850 & $\mathrm{C}_{13} \mathrm{H}_{11}^{+}$ & 167.0855 & 2.99 \\
\hline & & & 168.0845 & 167.0845 & $\mathrm{C}_{13} \mathrm{H}_{11}^{+}$ & 167.0855 & 5.98 \\
\hline & & & 157.0252 & 156.0252 & $\mathrm{C}_{7} \mathrm{H}_{8} \mathrm{O}_{2} \mathrm{~S}$ & 156.0245 & -4.49 \\
\hline \multirow[t]{3}{*}{ AMD6 } & 2.17 & MS-ES & 233.0560 & 232.0560 & $\mathrm{C}_{13} \mathrm{H}_{12} \mathrm{O}_{2} \mathrm{~S}$ & 232.0558 & -0.86 \\
\hline & & & 167.0851 & 167.0851 & $\mathrm{C}_{13} \mathrm{H}_{11}{ }^{+}$ & 167.0855 & 2.39 \\
\hline & & & 125.0341 & 124.0341 & $\mathrm{C}_{7} \mathrm{H}_{8} \mathrm{~S}$ & 124.0347 & 4.84 \\
\hline
\end{tabular}

Table 7: Observed $\mathrm{m} / \mathrm{z}$ values for the $[\mathrm{M}+\mathrm{H}]^{+}$ions and major fragments of $A M D$ and its degradation products in acidic condition.

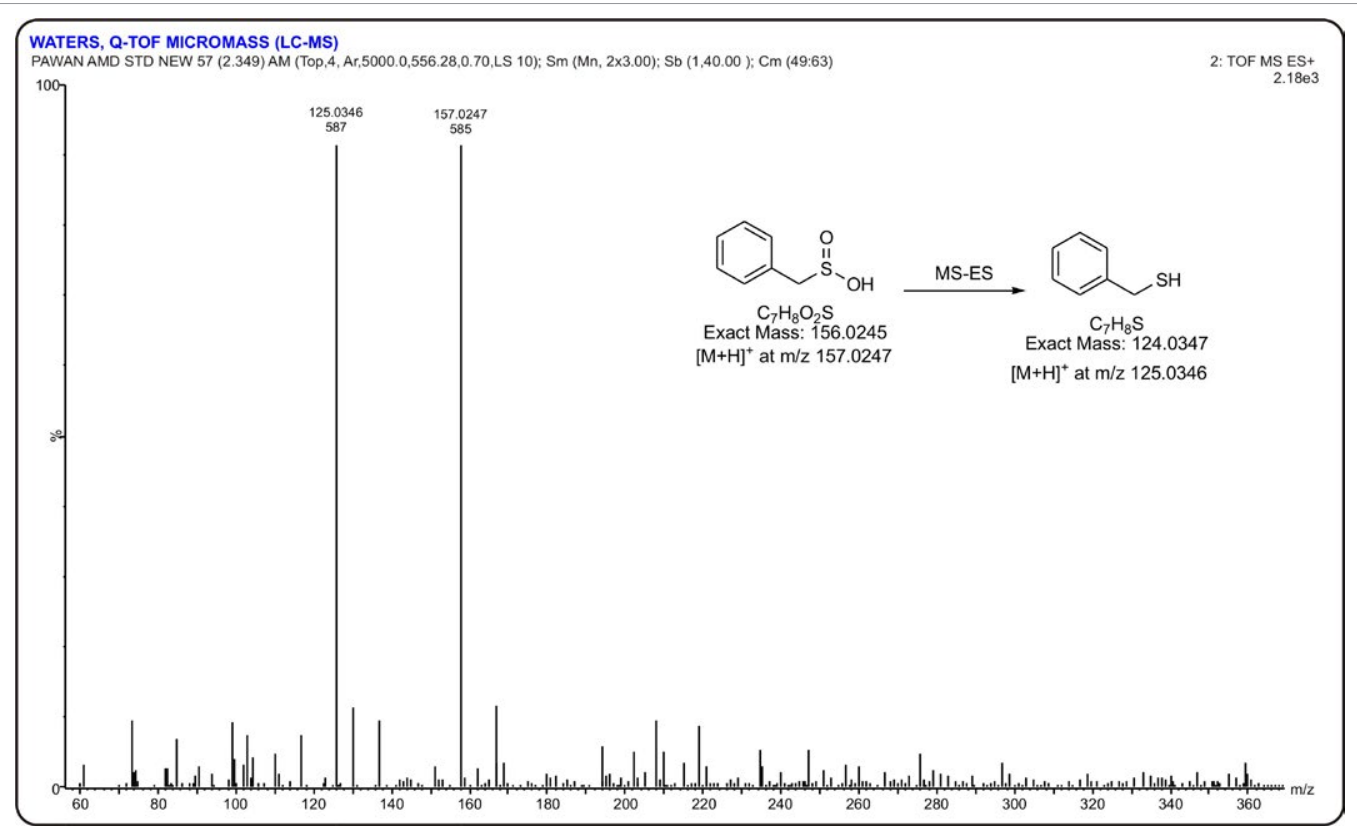

Figure 14: TOF MS-ES+ spectrum and proposed fragmentation pattern of AMD-Imp in standard AMD.

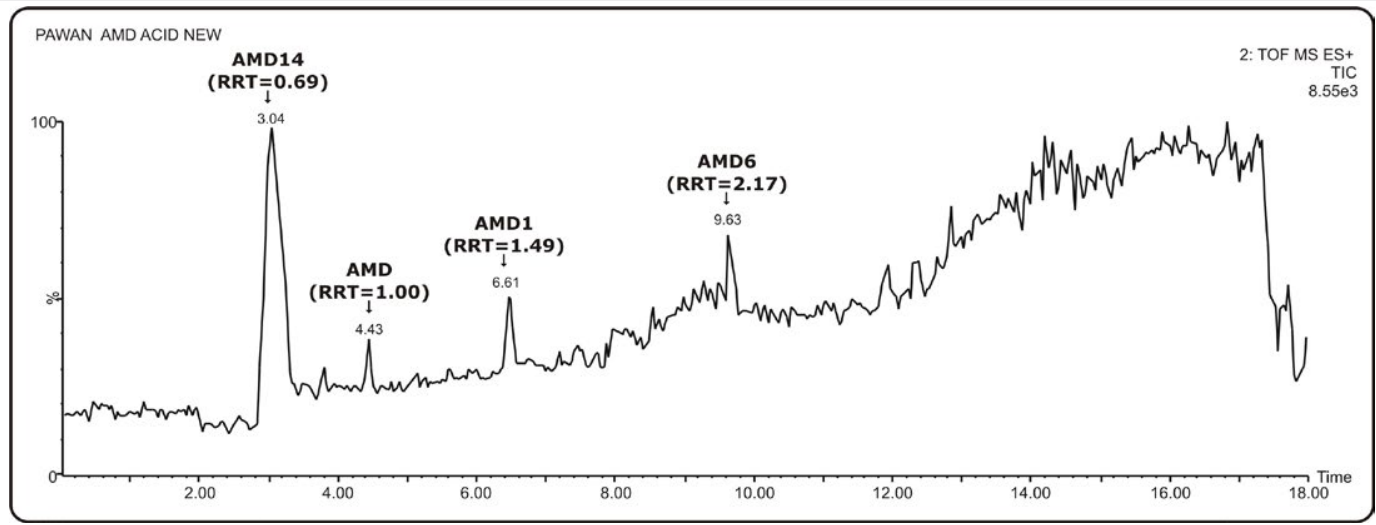

Figure 15: Chromatogram of degraded AMD in acidic condition by TOF MS ES+ scanning. 
Citation: Jain D, Basniwal PK (2016) Intrinsic Stability Study of Armodafinil Hydrochloride by Forced Degradation and Impurity Profiling. Pharm Anal Acta 7: 466. doi:10.4172/2153-2435.1000466

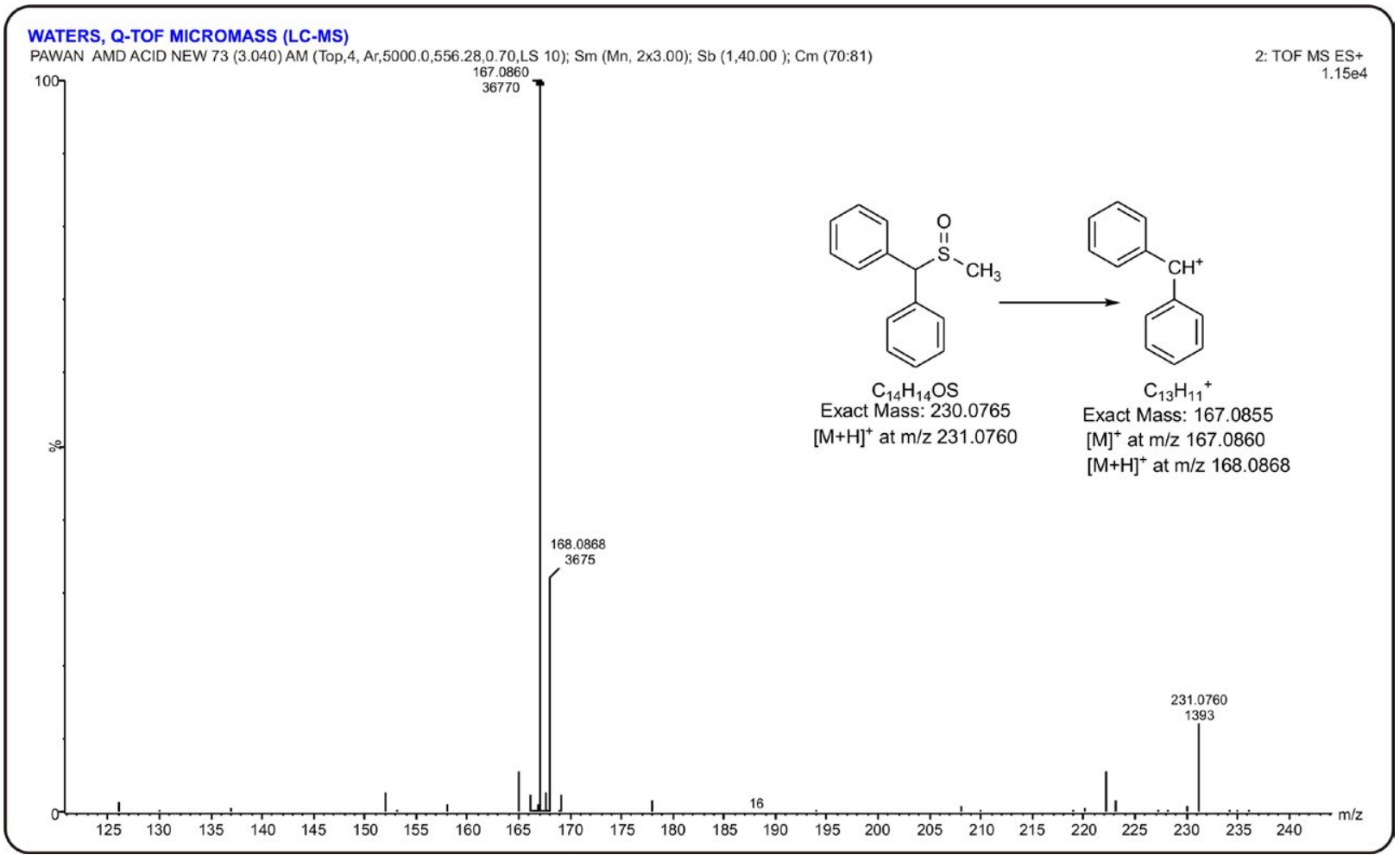

Figure 16: TOF MS-ES+ spectrum and proposed fragmentation pattern of AMD14 in acidic condition.

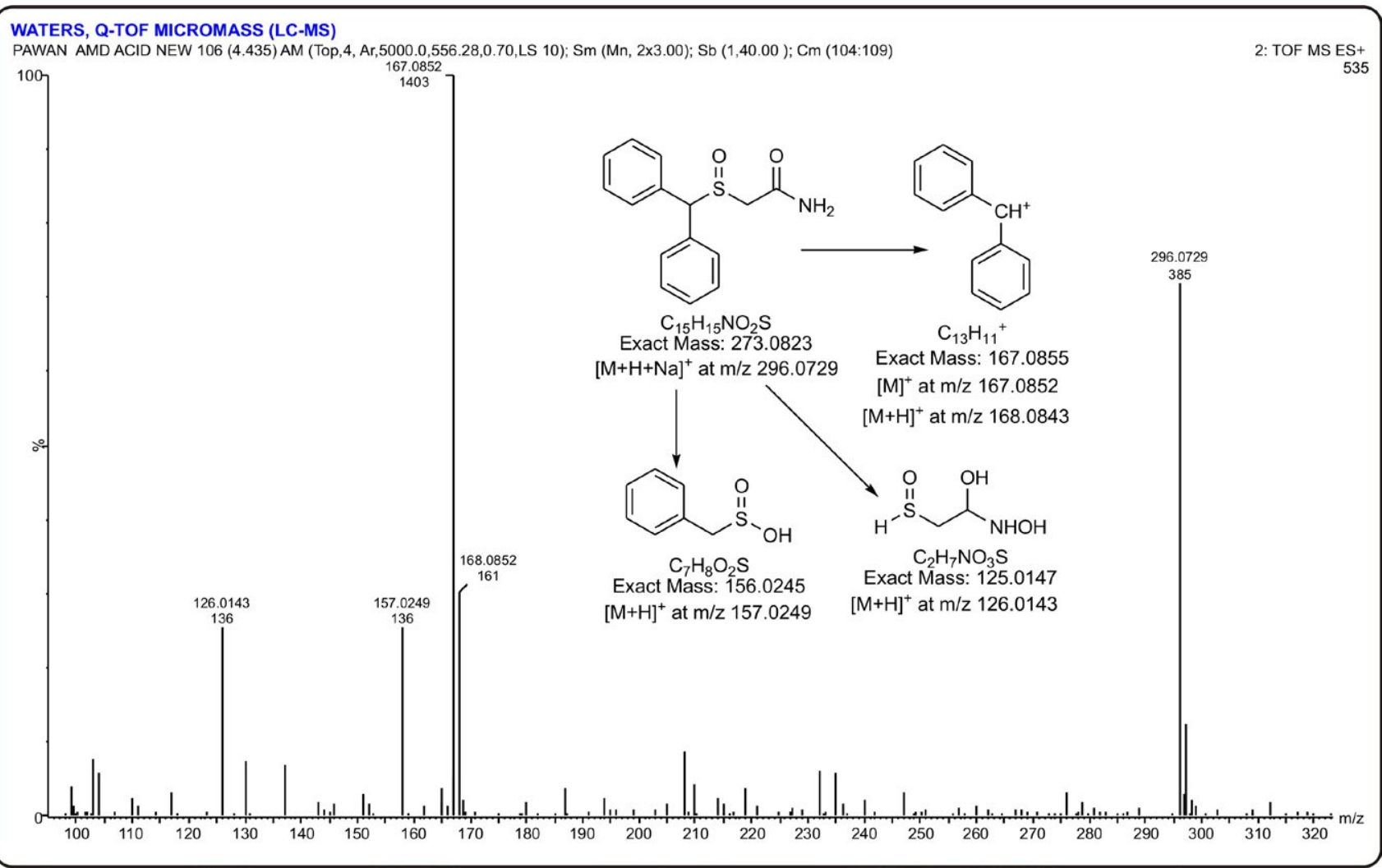

Figure 17: TOF MS-ES+ spectrum and proposed fragmentation pattern of AMD in acidic condition. 
Citation: Jain D, Basniwal PK (2016) Intrinsic Stability Study of Armodafinil Hydrochloride by Forced Degradation and Impurity Profiling. Pharm Anal Acta 7: 466. doi:10.4172/2153-2435.1000466

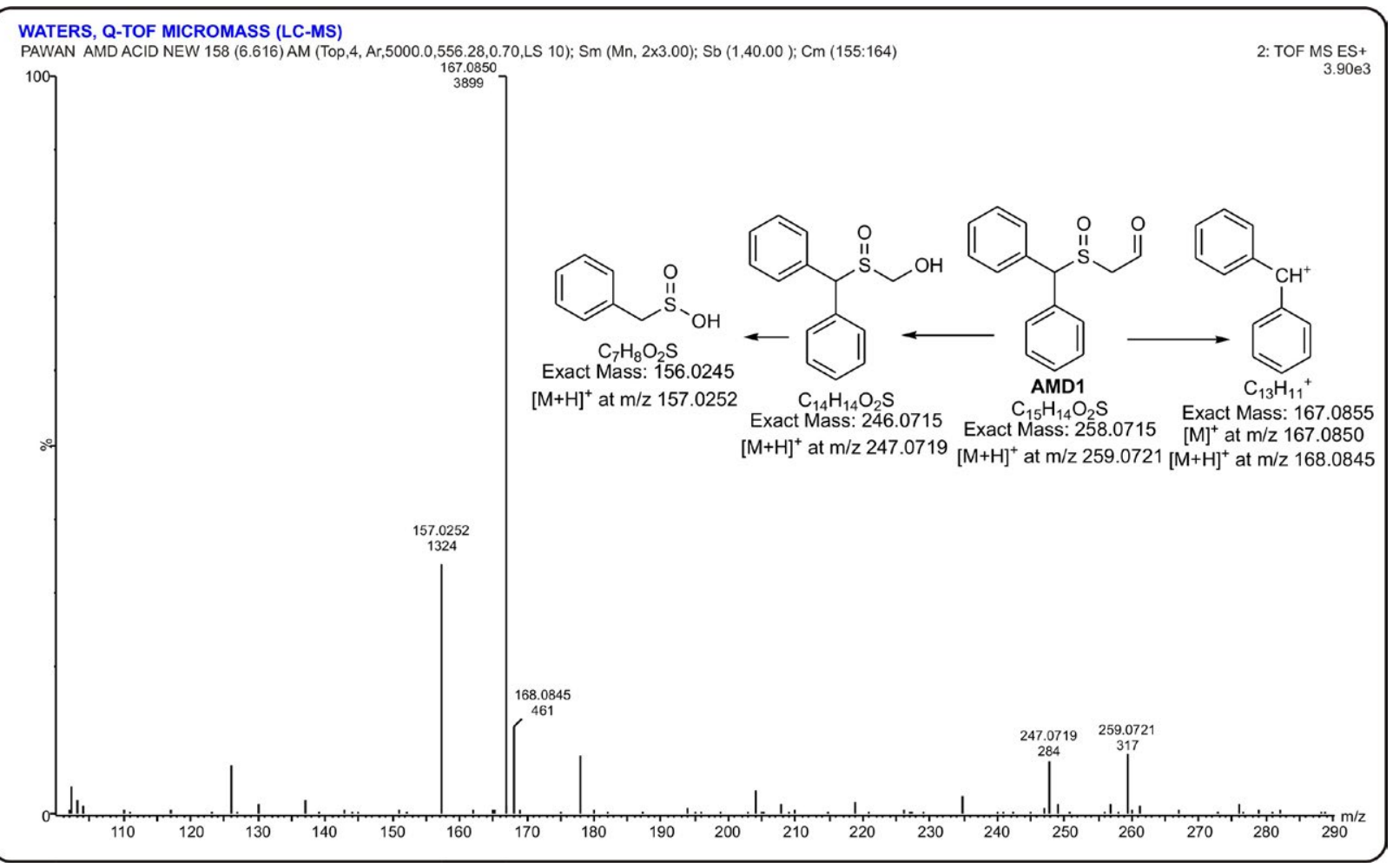

Figure 18: TOF MS-ES+ spectrum and proposed fragmentation pattern of AMD1 in acidic condition.

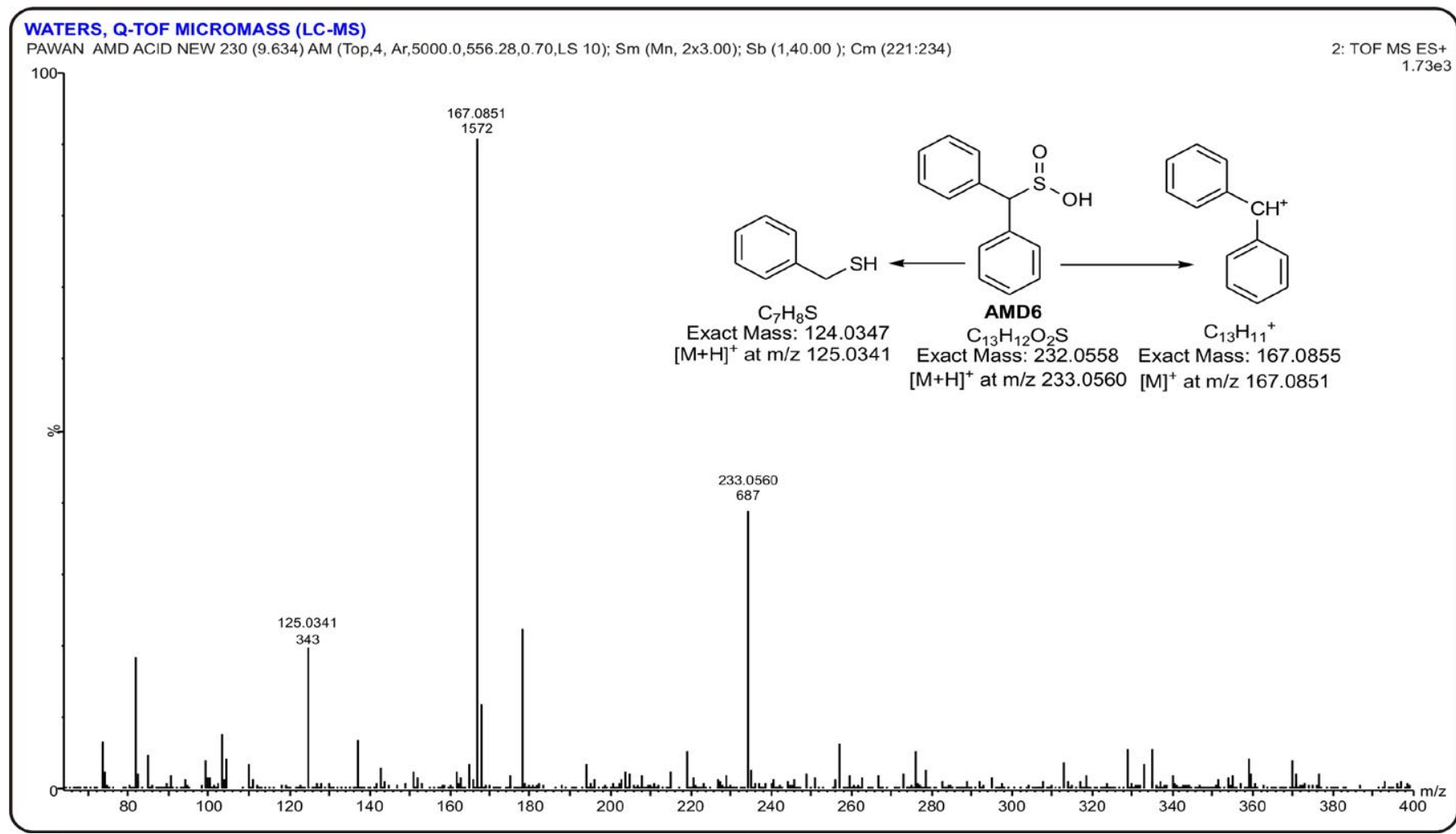

Figure 19: TOF MS-ES+ spectrum and proposed fragmentation pattern of AMD6 in acidic condition. 
Citation: Jain D, Basniwal PK (2016) Intrinsic Stability Study of Armodafinil Hydrochloride by Forced Degradation and Impurity Profiling. Pharm Anal Acta 7: 466. doi:10.4172/2153-2435.1000466

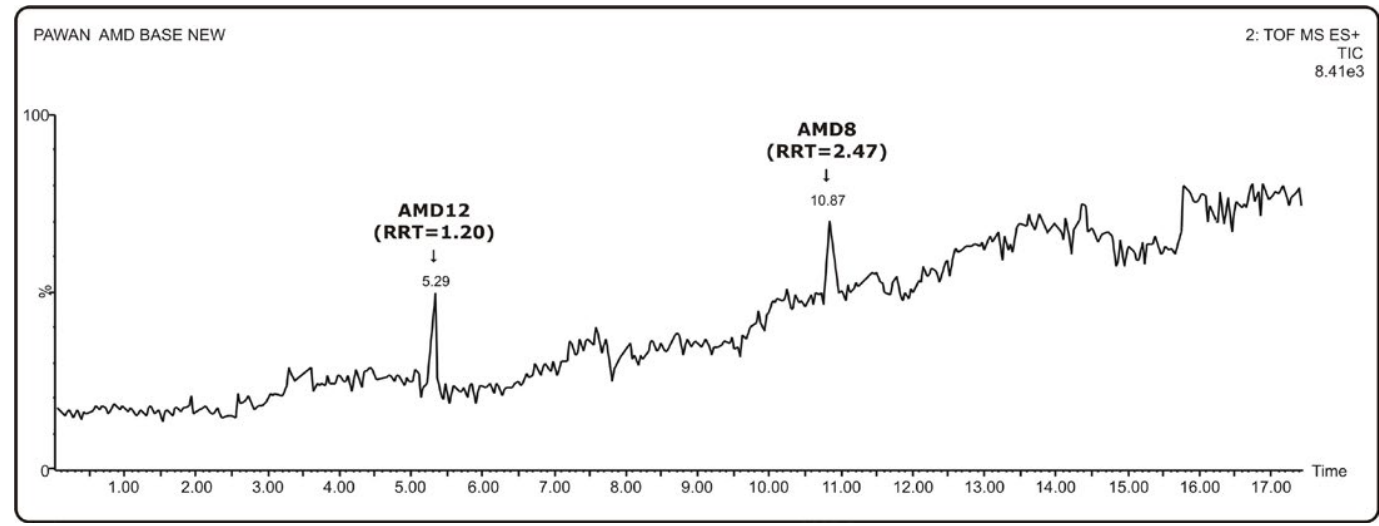

Figure 20: Chromatogram of degraded AMD in alkaline condition by TOF MS ES+ scanning.

as sodium 2-(benzhydrylsulfinyl) acetate. It was further supported by its product ion which was appeared with isotopic abundance (Figure 21 and Table 8).

AMD8 has been identified as 2-(benzhydrylsulfinyl) acetic acid, which protonated molecular ion $[\mathrm{M}+\mathrm{H}]^{+}$was observed at $\mathrm{m} / \mathrm{z}$ 275.0660. It was also advocated by its daughter products which were appeared at m/z 125.0349 and 167.0860 with less than 5 unit error in mass (Figure 22 and Table 8).

Neutral degradation: Two degradation product of AMD in neutral condition were identified by TOF MS ES+ scanning which were eluted at RRT of 2.47 (AMD8) and 3.10 (AMD11) during HRMS analysis of neutral degradation of samples of AMD (Figure 23).

Drug AMD was also observed and characterized in neutral condition, which has shown sodium adduct and its isotopic adduct at $\mathrm{m} / \mathrm{z} 296.0834$ and 297.0830, respectively. It was further fragmented into product ion and observed at $\mathrm{m} / \mathrm{z} 167.0852$ with its isotopic abundance (Figure 23 and Table 9).

Fragmentation pattern of 2-(benzhydrylsulfinyl) acetic acid recommends the proposed structure of AMD8 which was observed as: $274.0664 \rightarrow 234.0715 \rightarrow 218.0765 \rightarrow 124.0347$ (Figures 24 and 25). The diphenylmethyl ion (167.0855) is also observed in mass spectrum of AMD8 which is present in the most of mass spectrum. The ppm error in mass is less than 5 for entire postulated fragment including AMD8 (Table 9).

The mass spectrum of AMD11 has shown molecular protonated mass abundance $[\mathrm{M}+\mathrm{H}]^{+}$at 235.0704 with 4.70 ppm error in mass. Its two different fragmentation pattern $(234.0715 \rightarrow 215.0525 \rightarrow 167.0855$ and $234.0715 \rightarrow 218.0765 \rightarrow 124.0347)$ have supported the purposed structure (Figure 26 and Table 9).

An impurity (AMD-Imp) was eluted at RRT of 0.53 and postulated as phenylmethanesulfinic acid. AMD is amide derivative and converted to its aldehyde derivative as AMD1 [2-(benzhydrylsulfinyl) acetaldehyde] in acidic medium. It is advocated by Vilsmeier-Haack reaction, which is the conversion of a substituted amide to an aryl aldehyde or ketone. The aldehyde is further degraded into methylsulfinyl diphenylmethane (AMD14), which is further converted to diphenylmethanesulfinic acid (AMD6) (Figure 27). It is readily hydrolyzed to carboxylic acid in alkaline condition. Two degradation products were identified as carboxylic acid (AMD8) and its sodium salt (AMD12), respectively. These were identified as sodium 2-(benzhydrylsulfinyl) acetate
(AMD12) and 2-(benzhydrylsulfinyl) acetic acid (AMD8) (Figure 27). Two degradation product, 2-(benzhydrylsulfinyl) acetic acid (AMD8) and diphenylmethanesulfoxylic acid (AMD11) were identified in neutral condition. Both are hydrolyzed product of sulfinylacetamide side chain of the AMD (Figure 27).

\begin{tabular}{|c|c|c|c|c|c|c|c|}
\hline $\begin{array}{c}\text { Analyte } \\
\text { Code }\end{array}$ & $\begin{array}{c}\text { RRT } \\
\text { in } \\
\text { LC- } \\
\text { MS }\end{array}$ & $\begin{array}{c}\text { MS-ES } \\
\text { or MS- } \\
\text { MS }\end{array}$ & $\begin{array}{c}\mathbf{m} / \mathbf{z} \\
\text { value }\end{array}$ & $\begin{array}{c}\text { Measured } \\
\text { Mass }\end{array}$ & $\begin{array}{c}\text { Best } \\
\text { possible } \\
\text { molecular } \\
\text { formulae }\end{array}$ & $\begin{array}{c}\text { Exact } \\
\text { Mass }\end{array}$ & $\begin{array}{c}\text { PPM } \\
\text { error }\end{array}$ \\
\hline AMD12 & 1.20 & MS-ES & 297.0492 & 296.0492 & $\mathrm{C}_{15} \mathrm{H}_{13} \mathrm{NaO}_{3} \mathrm{~S}$ & 296.0483 & -3.04 \\
\hline & & & 167.0852 & 167.0852 & $\mathrm{C}_{13} \mathrm{H}_{11}{ }^{+}$ & 167.0855 & 1.80 \\
\hline AMD8 & 2.47 & MS-ES & 275.0660 & 274.0660 & $\mathrm{C}_{15} \mathrm{H}_{14} \mathrm{O}_{3} \mathrm{~S}$ & 274.0664 & 1.46 \\
\hline & & & 167.0860 & 167.0860 & $\mathrm{C}_{13} \mathrm{H}_{11}{ }^{+}$ & 167.0855 & -2.99 \\
\hline & & & 125.0349 & 124.0349 & $\mathrm{C}_{7} \mathrm{H}_{8} \mathrm{~S}$ & 124.0347 & -1.61 \\
\hline
\end{tabular}

Table 8: Observed $\mathrm{m} / \mathrm{z}$ values for the $[\mathrm{M}+\mathrm{H}]^{+}$ions and major fragments of AMD and its degradation products in alkaline condition.

\begin{tabular}{|c|c|c|c|c|c|c|c|}
\hline $\begin{array}{c}\text { Analyte } \\
\text { Code }\end{array}$ & $\begin{array}{l}\text { RRT } \\
\text { in } \\
\text { LC- } \\
\text { MS }\end{array}$ & $\begin{array}{c}\text { MS-ES } \\
\text { or MS- } \\
\text { MS }\end{array}$ & $\begin{array}{c}\mathrm{m} / \mathbf{z} \\
\text { value }\end{array}$ & $\begin{array}{c}\text { Measured } \\
\text { Mass }\end{array}$ & $\begin{array}{c}\text { Best } \\
\text { possible } \\
\text { molecular } \\
\text { formulae }\end{array}$ & $\begin{array}{l}\text { Exact } \\
\text { Mass }\end{array}$ & $\begin{array}{l}\text { PPM } \\
\text { error }\end{array}$ \\
\hline \multirow[t]{4}{*}{ AMD } & 1.00 & MS-ES & 296.0834 & 273.0834 & $\mathrm{C}_{15} \mathrm{H}_{15} \mathrm{NO}_{2} \mathrm{~S}$ & 273.0823 & -4.03 \\
\hline & & & 297.0830 & 273.0830 & $\mathrm{C}_{15} \mathrm{H}_{15} \mathrm{NO}_{2} \mathrm{~S}$ & 273.0823 & -2.56 \\
\hline & & & 167.0852 & 167.0852 & $\mathrm{C}_{13} \mathrm{H}_{11}^{+}$ & 167.0855 & 1.80 \\
\hline & & & 168.0849 & 167.0849 & $\mathrm{C}_{13} \mathrm{H}_{11}^{+}$ & 167.0855 & 3.59 \\
\hline \multirow[t]{5}{*}{ AMD8 } & 2.47 & MS-ES & 275.0652 & 274.0652 & $\mathrm{C}_{15} \mathrm{H}_{14} \mathrm{O}_{3} \mathrm{~S}$ & 274.0664 & 4.38 \\
\hline & & & 235.0724 & 234.0724 & $\mathrm{C}_{13} \mathrm{H}_{14} \mathrm{O}_{2} \mathrm{~S}$ & 234.0715 & -3.84 \\
\hline & & & 219.0761 & 218.0761 & $\mathrm{C}_{13} \mathrm{H}_{14} \mathrm{OS}$ & 218.0765 & 1.83 \\
\hline & & & 167.0853 & 167.0853 & $\mathrm{C}_{13} \mathrm{H}_{11}{ }^{+}$ & 167.0855 & 1.20 \\
\hline & & & 125.0341 & 124.0341 & $\mathrm{C}_{7} \mathrm{H}_{8} \mathrm{~S}$ & 124.0347 & 4.84 \\
\hline \multirow[t]{5}{*}{ AMD11 } & 3.10 & MS-ES & 235.0704 & 234.0704 & $\mathrm{C}_{13} \mathrm{H}_{14} \mathrm{O}_{2} \mathrm{~S}$ & 234.0715 & 4.70 \\
\hline & & & 219.0751 & 218.0751 & $\mathrm{C}_{13} \mathrm{H}_{14} \mathrm{OS}$ & 218.0765 & 6.42 \\
\hline & & & 215.0520 & 215.0520 & $\mathrm{C}_{13} \mathrm{H}_{11} \mathrm{OS}^{+}$ & 215.0525 & 2.33 \\
\hline & & & 167.0850 & 167.0850 & $\mathrm{C}_{13} \mathrm{H}_{11}^{+}$ & 167.0855 & 2.99 \\
\hline & & & 125.0351 & 124.0351 & $\mathrm{C}_{7} \mathrm{H}_{8} \mathrm{~S}$ & 124.0347 & -3.22 \\
\hline
\end{tabular}

Table 9: Observed $\mathrm{m} / \mathrm{z}$ values for the $[\mathrm{M}+\mathrm{H}]^{+}$ions and major fragments of $A M D$ and its degradation products in neutral condition. 
Citation: Jain D, Basniwal PK (2016) Intrinsic Stability Study of Armodafinil Hydrochloride by Forced Degradation and Impurity Profiling. Pharm Anal Acta 7: 466. doi:10.4172/2153-2435.1000466

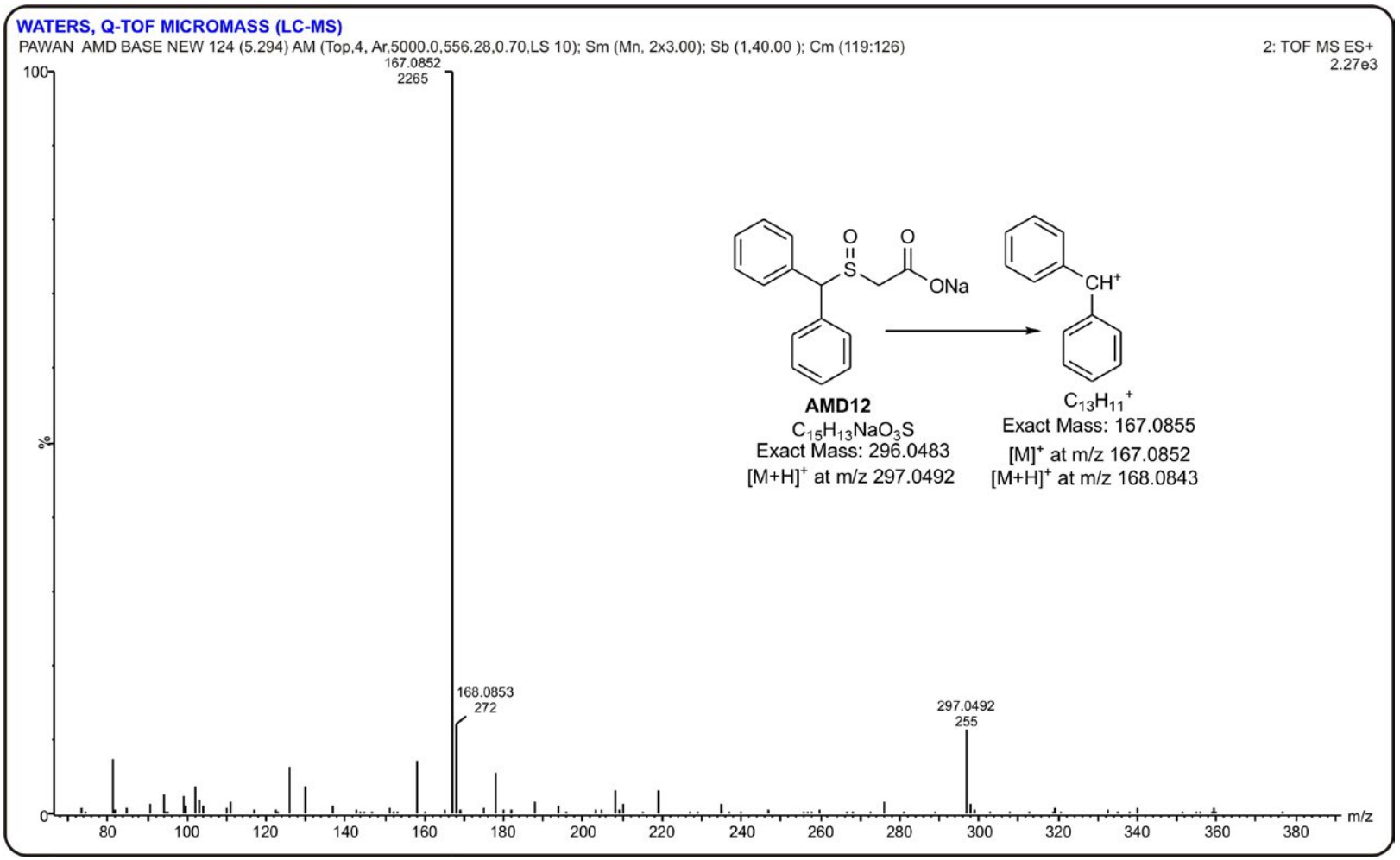

Figure 21: TOF MS-ES+ spectrum and proposed fragmentation pattern of AMD12 in alkaline condition.

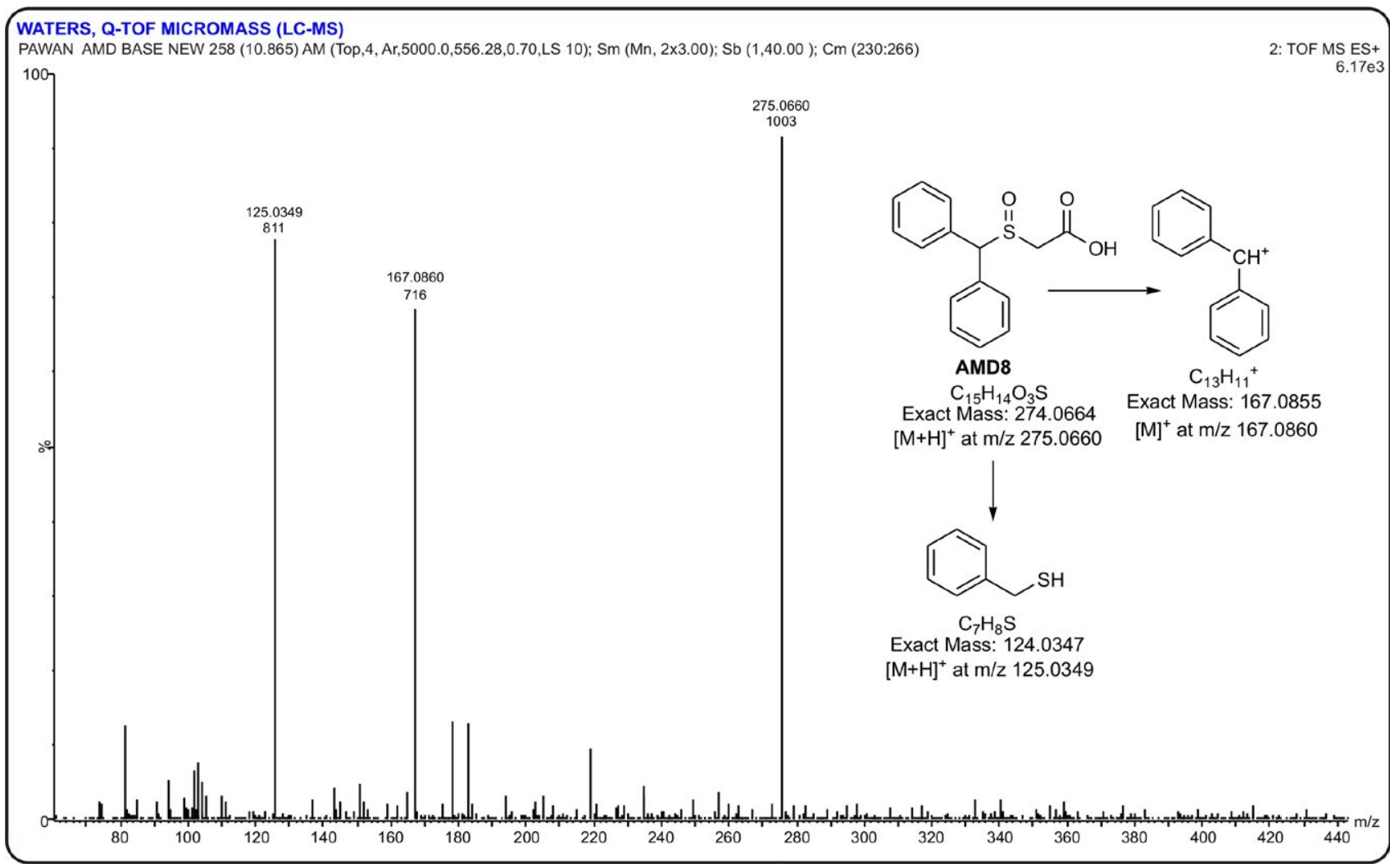

Figure 22: TOF MS-ES+ spectrum and proposed fragmentation pattern of AMD8 in alkaline condition. 


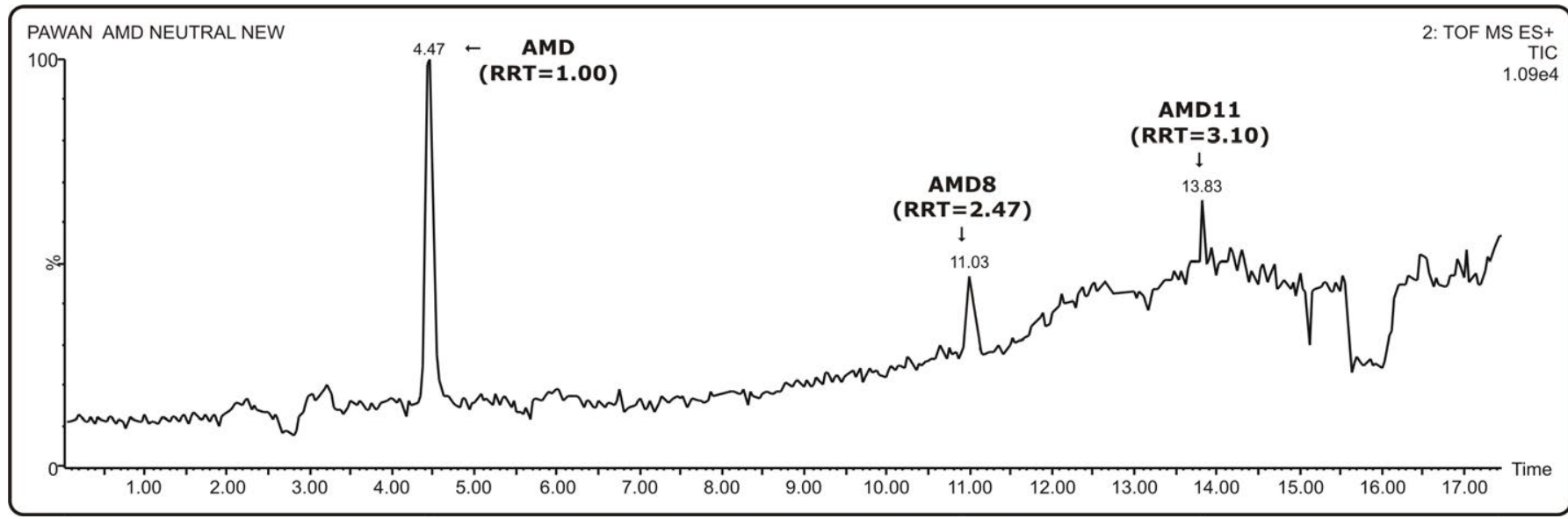

Figure 23: Chromatogram of degraded AMD in neutral condition by TOF MS ES+ scanning

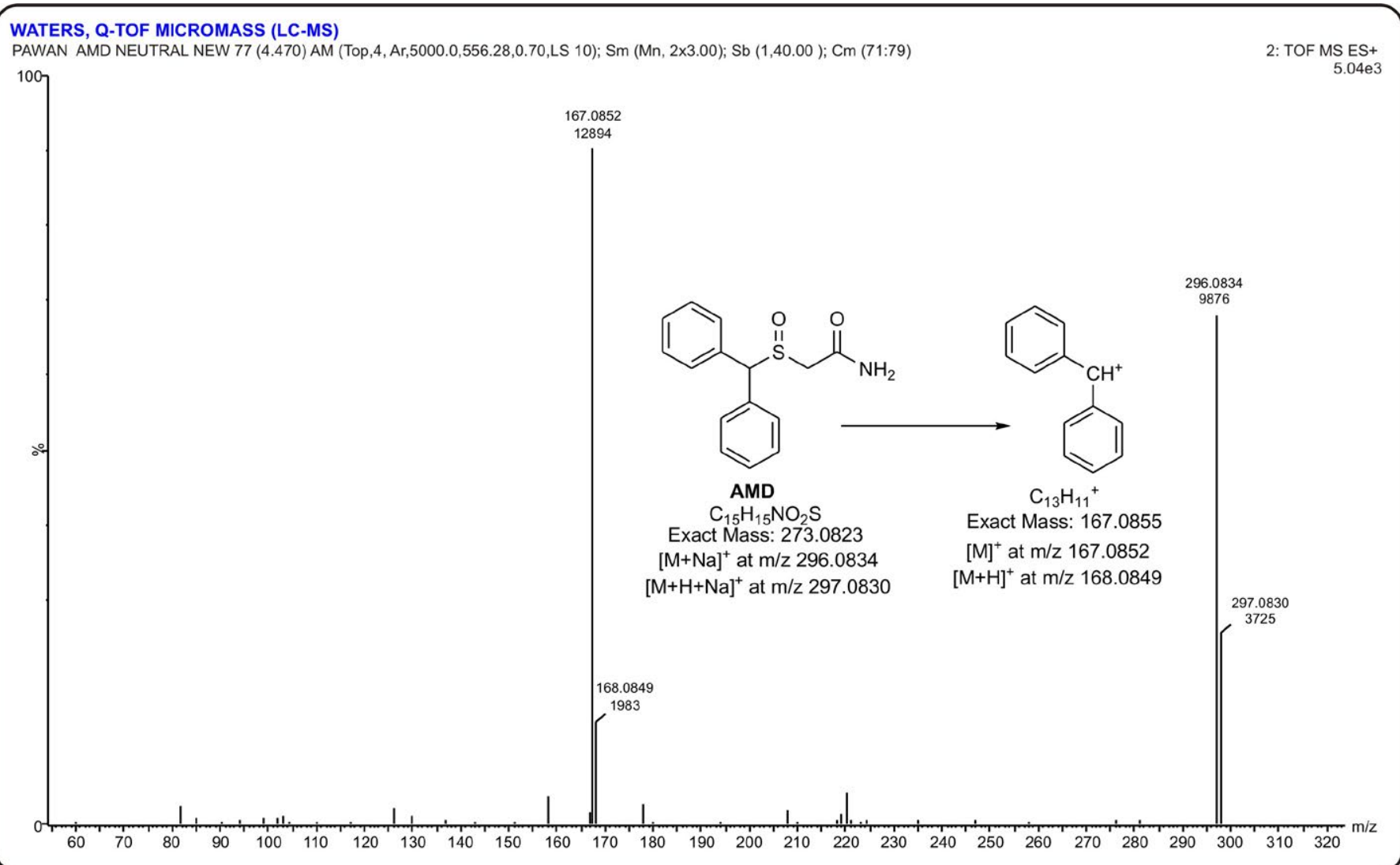

Figure 24: TOF MS-ES+ spectrum and proposed fragmentation pattern of AMD in neutral condition.

\section{Conclusion}

Forced degradation and impurity profiling of armodafinil was established by RP-HPLC-DAD-HRMS method. Structure of one impurity present in drug, structure of degradation products formed during hydrolytic degradation (acidic, alkaline and neutral) and degradation pathways of drug in hydrolytic condition have been postulated.
The authors confirm that this article content has no conflict of interest.

\section{Acknowledgement}

One of the authors, Pawan Kumar Basniwal, is earnestly indebted to the Science and Engineering Research Board (SERB), DST, New Delhi, for the financial support for this research work under Fast Track Scheme for Young Scientists [SR/FT/LS-187/2008 (G)]. The authors are highly thankful to the Head 
Citation: Jain D, Basniwal PK (2016) Intrinsic Stability Study of Armodafinil Hydrochloride by Forced Degradation and Impurity Profiling. Pharm Anal Acta 7: 466. doi:10.4172/2153-2435.1000466

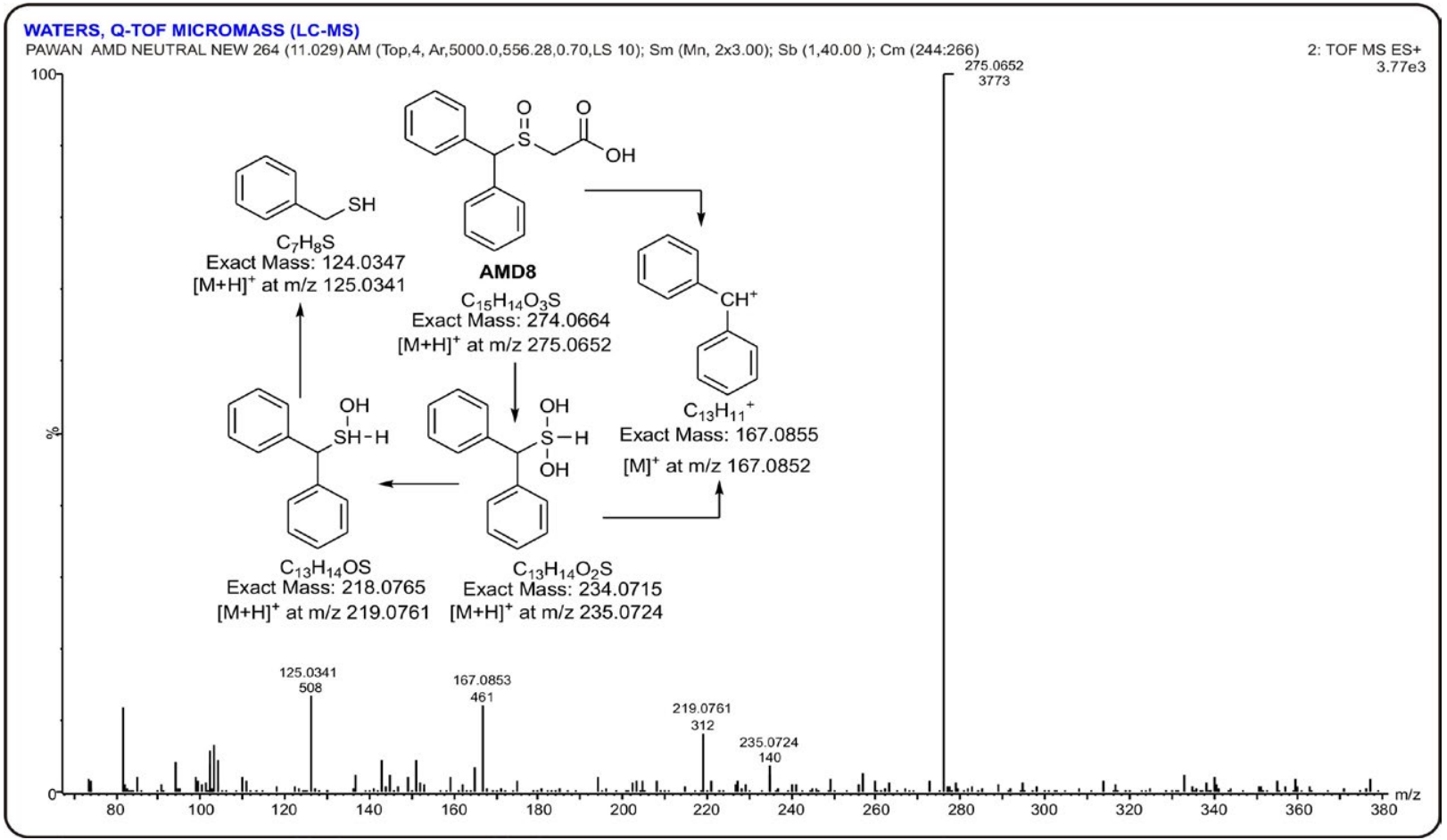

Figure 25: TOF MS-ES+ spectrum and proposed fragmentation pattern of AMD8 in neutral condition.

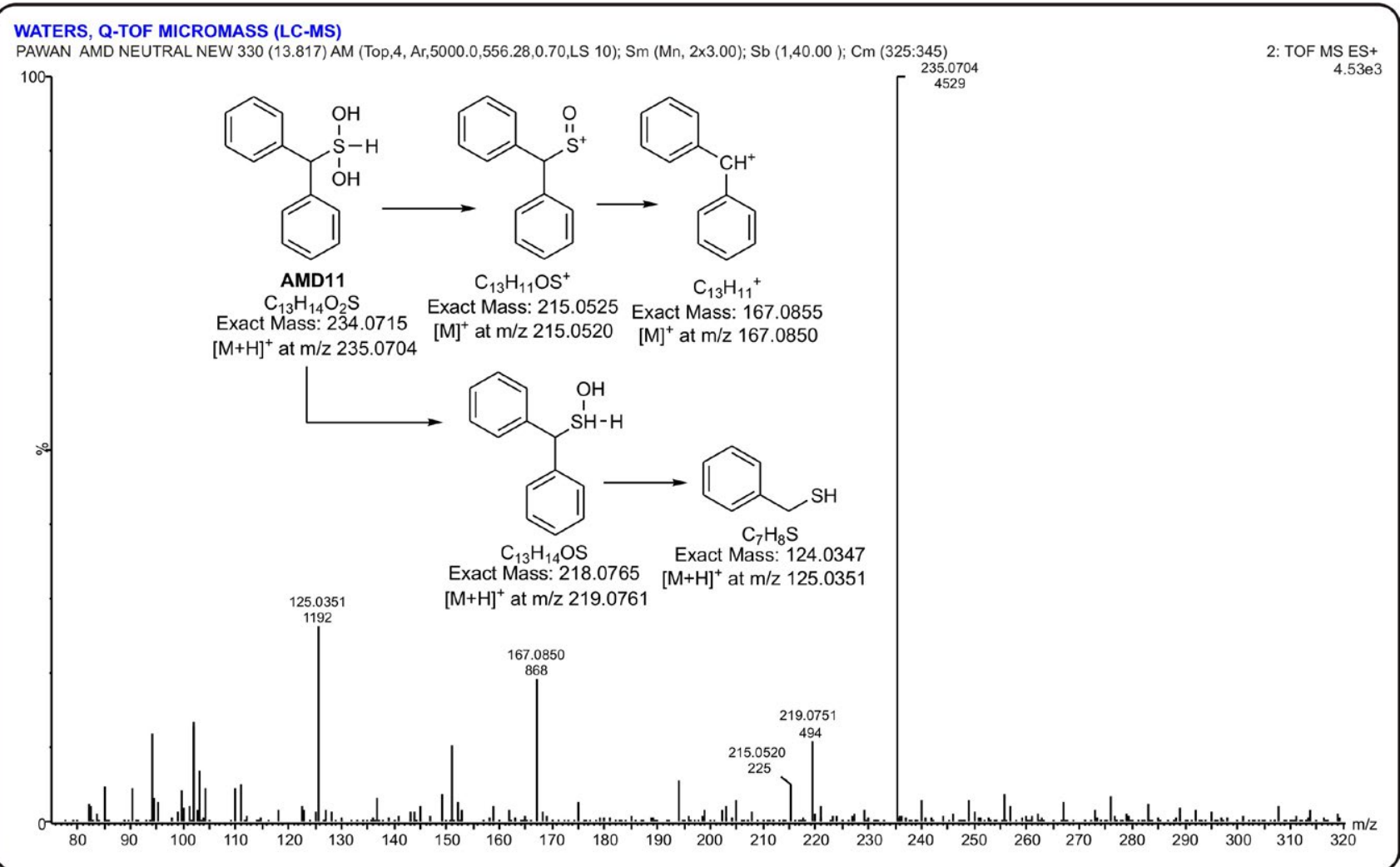

Figure 26: TOF MS-ES+ spectrum and proposed fragmentation pattern of AMD11in neutral condition. 


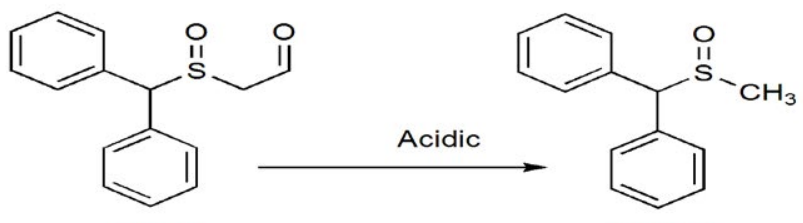

AMD1

2-(Benzhydrylsulfinyl)acetaldehyde<smiles>NC(=O)CS(=O)C(c1ccccc1)c1ccccc1</smiles>

Methylsulfinyldiphenylmethane

Acidic<smiles>O=S(O)C(c1ccccc1)c1ccccc1</smiles>

AMD6

Diphenylmethanesulfinic acid

2-(Benzhydrylsulfinyl)acetamide

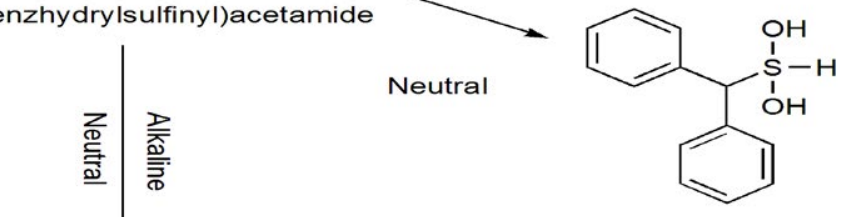

AMD11

Diphenylmethanesulfoxylic acid<smiles>O=C(O)CS(=O)C(c1ccccc1)c1ccccc1</smiles>

AMD8<smiles>O=C(CS(=O)C(c1ccccc1)c1ccccc1)O[Na]</smiles>

AMD12

2-(benzhydrylsulfinyl)acetic acid Sodium 2-(benzhydrylsulfinyl)acetate<smiles>O=S(O)Cc1ccccc1</smiles>

AMD-Imp

Phenylmethanesulfinic acid

Figure 27: Proposed structure of AMD-Imp and degradation pathway of AMD in acidic, alkaline and neutral condition.

of the School of Pharmaceutical Sciences, RGPV, Bhopal, and the Principal of the LBS College of Pharmacy, Jaipur, for providing the experimental facilities for this research work.

\section{References}

1. Keating GM, Raffin MJ (2005) Modafinil: a review of its use in excessive sleepiness associated with obstructive sleep apnoea / hypopnoea syndrome and shift work sleep disorder. CNS Drugs 19: 785-803.

2. Rao RN, Shinde DD, Talluri MVNK, Agawane SB (2008) LC-ESI-MS determination and pharmacokinetics of adrafinil in rats. J Chromatography $\mathrm{B}$ 873: 119-123.

3. Devadiga MP, Anandan P, Mukhopadhyay A (2011) Development of a rapid and sensitive method for estimation of armodafinil in human plasma by LCMS / MS. Int J Applied Bio Pharm Tech 2: 323-327.

4. Schwertnera HA, Kong SB (2005) Determination of modafinil in plasma and urine by reversed phase high-performance liquid-chromatography. J Pharm Biomed Anal 37: 475-479.

5. Rao RN, Shinde DD, Talluri MVK (2008) Enantioselective HPLC resolution of synthetic intermediates of armodafinil and related substances. J Sep Sci 31: 981-989.

6. Rao RN, Shinde DD, Srinivas VRR (2009) LC-MS of novel narcoepileptics and related substances. J Sep Sci 32: 1312-1322.
7. Wang W, Xiang S, Zhou X, Ji Y, Xiang B (2011) Enantiomeric separation and determination of the enantiomeric impurity of armodafinil by capillary electrophoresis with sulfobutyl ether- $\beta$-cyclodextrin as chiral selector. Molecules 17: 303-314.

8. Jain D, Basniwal PK (2013) Forced degradation and impurity profiling: recent trends in analytical perspectives. J Pharm Biom Ana 86: 11-35.

9. $\mathrm{ICH}(2000)$ Text on validation of analytical procedures. International conference on harmonization of technical requirements for registration of pharmaceutical for human use. Geneva.

10. ICH (2000) Validation of analytical procedure: methodology. International conference on harmonization of technical requirements for registration of pharmaceutical for human Use. Geneva. 